Colloid and Interface Science

Elsevier Editorial System(tm) for Journal of

Manuscript Draft

Manuscript Number: JCIS-15-1854R1

Title: Effects of bleaching on osteoclast activity and their modulation by osteostatin and fibroblast growth factor 2

Article Type: Full length article

Section/Category: D. Interfacial Processes, Capillarity and Wetting

Keywords: Dental bleaching; external cervical resorption; osteoclast; fibroblast growth factor 2; osteostatin

Corresponding Author: Prof. Maria Vallet-Regí,

Corresponding Author's Institution: Universidad Complutense

First Author: Carolina Torres-Rodríguez, PhD

Order of Authors: Carolina Torres-Rodríguez, PhD; M.Teresa Portolés, Prof; M. Concepción Matesanz ; Javier s Linare; M. José Feito; Isabel Izquierdo-Barba ; Pedro Esbrit; Maria Vallet-Regí

Abstract: Hypothesis: Dental bleaching with $\mathrm{H} 2 \mathrm{O} 2$ is a common daily practice in dentistry to correct discoloration of anterior teeth. The aim of this study has been to determine whether this treatment of human teeth affects growth, differentiation and activity of osteoclast-like cells, as well as the putative modulatory action of osteostatin and fibroblast growth factor 2 (FGF-2).

Experiments: Previously to the in vitro assays, structural, physicalchemical and morphological features of teeth after bleaching were studied. Osteoclast-like cells were cultured on human dentin disks, pretreated or not with 38\% $\mathrm{H} 2 \mathrm{O} 2$ bleaching gel, in the presence or absence of osteostatin (100 nM) or FGF-2 (1 ng/ml). Cell proliferation and viability, intracellular content of reactive oxygen species (ROS), proinflammatory cytokine (IL- 6 and TNF $\alpha$ ) secretion and resorption activity were evaluated.

Findings: Bleaching treatment failed to affect either the structural or the chemical features of both enamel and dentin, except for slight morphological changes, increased porosity in the most superficial parts (enamel), and a moderate increase in the wettability degree. In this scenario, bleaching produced an increased osteoclast-like cell proliferation but decreased cell viability and cytokine secretion, while it augmented resorption activity on dentin. The presence of either osteostatin or FGF-2 reduced the osteoclast-like cell proliferation induced by bleaching. FGF-2 enhanced ROS content, whereas osteostatin decreased ROS but increased TNF $\alpha$ secretion. The bleaching effect on resorption activity was increased by osteostatin, but this effect was less evident with FGF-2.

Conclusions: These findings further confirm the deleterious effects of tooth bleaching by affecting osteoclast growth and function as well as different modulatory actions of osteostatin and FGF-2. 

Prof. María Vallet-Regí,

Departamento de Química Inorgánica y Bioinorgánica

Facultad de Farmacia

Universidad Complutense

28040, Madrid, Spain

Tels: +34-913941861/3941843; FAX: +34-91-3941786

e-mail: vallet@farm.ucm.es

Madrid, September $10^{\text {th }} 2015$

Dear Prof. Martin Malmsten,

Thank you very much for your kind e-mail concerning the Manuscript Ms. No.: JCIS-151854, entitled "Effects of bleaching on osteoclast activity and their modulation by osteostatin and fibroblast growth factor 2 ".

We sincerely appreciate reviewers' remarks to improve the article and we have modified our manuscript following their recommendations. We have included additional physical-chemical and structural characterization to determine the effects with the bleaching. Moreover, the Conclusion has been improved in the revised manuscript according to your technical notes. The modifications are highlighted in the manuscript and detailed responses to the reviewers' comments are included bellow.

We hope that the revised version of our manuscript is now appropriate for publication in Journal of Colloid and Interface Science.

Thank you for your kind consideration of our work.

Sincerely,

Prof. María Vallet-Regí. 


\section{Response to the Reviewers:}

Reviewers' comments:

Reviewer \#2: The ms reports on an investigation of the effects of teeth bleaching by $\mathrm{H} 2 \mathrm{O} 2$ on osteoclast activities and their modulation by osteostatin and fibroblast growth factor 2 . The ms provides a nice brief biological investigation of a well-specified issues, but essentially no surface chemical information. Therefore, the authors must address the following issues before this ms can be further considered for publication:

1) Surface characterization is insufficient for a surface chemistry journal such as JCIS. Thus, additional surface characterization is needed regarding the effect of bleaching on surface energy (contact angle), topography (AFM), chemical composition (XPS), and surface charge. Without a rudimentary surface characterization, this ms can not be published in JCIS, even as a short communication.

Certainly, the authors totally agree with the referee's comment and additional physical-chemical and structural characterization has been included. In this sense, chemical characterization by a rigorous studies by X-Ray energy dispersive (EDS), electron probe microanalysis (EPMA) has been performed before and after bleaching. Moroever, structural characterization by X-Ray powder diffraction has been also carried out. Furthermore, contact angles were also measured to estimate the wettability of the samples. Thus, two news figures (Fig.3 and Fig.4) and one table (table 1) have been included.

2) Saliva will of course have a major importance on cell interactions with the teeth surfaces. Experiments on saliva protein adsorption should therefore be performed (see, e.g., previous work by Arnebrant et al for methodology

We agree with the reviewer about the important functions of saliva in the preservation of the teeth integrity and the relevance of saliva protein adsorption on the teeth surface (Svendsen, Lindh, Elofsson, Arnebrant, J Colloid Interface Sci 2008, 321, 52-59). In this sense, many studies have been performed on this aspect showing that the properties of salivary films formed at the solid-liquid interface depend on the saliva composition and especially on the physical-chemical characteristics of the substrate (Barrantes, Arnebrant, Lindh, Colloids and Surfaces A: Physicochem Eng Aspects 2014, 442: 56-62). Concerning the composition of saliva, salivary protein profiles are substantially modified by age and diet, which has an impact on the abundance of some proteins (Morzel, Palicki, Chabanet, Lucchi, Ducoroy, Chambon, Nicklaus, ArcH Oral Biol 2011, 56:634-642). However, the aim of our study has been to determine whether hydrogen peroxide treatment affects growth, differentiation and activity of osteoclast-like cells, as well as the putative modulatory action of osteostatin and fibroblast growth factor 2 , in the absence of other protection agents. For all these 
reasons, authors thank the reviewer and will take his(her) suggestions into account for future studies. 


\section{Response to the Reviewers:}

Reviewers' comments:

Reviewer \#2: The ms reports on an investigation of the effects of teeth bleaching by $\mathrm{H} 2 \mathrm{O} 2$ on osteoclast activities and their modulation by osteostatin and fibroblast growth factor 2 . The ms provides a nice brief biological investigation of a well-specified issues, but essentially no surface chemical information. Therefore, the authors must address the following issues before this ms can be further considered for publication:

1) Surface characterization is insufficient for a surface chemistry journal such as JCIS. Thus, additional surface characterization is needed regarding the effect of bleaching on surface energy (contact angle), topography (AFM), chemical composition (XPS), and surface charge. Without a rudimentary surface characterization, this ms can not be published in JCIS, even as a short communication.

Certainly, the authors totally agree with the referee's comment and additional physical-chemical and structural characterization has been included. In this sense, chemical characterization by a rigorous studies by $X$-Ray energy dispersive (EDS), electron probe microanalysis (EPMA) has been performed before and after bleaching. Moroever, structural characterization by $X$-Ray powder diffraction has been also carried out. Furthermore, contact angles were also measured to estimate the wettability of the samples. Thus, two news figures (Fig.3 and Fig.4) and one table (table 1) have been included.

2) Saliva will of course have a major importance on cell interactions with the teeth surfaces. Experiments on saliva protein adsorption should therefore be performed (see, e.g., previous work by Arnebrant et al for methodology

We agree with the reviewer about the important functions of saliva in the preservation of the teeth integrity and the relevance of saliva protein adsorption on the teeth surface (Svendsen, Lindh, Elofsson, Arnebrant, J Colloid Interface Sci 2008, 321, 52-59). In this sense, many studies have been performed on this aspect showing that the properties of salivary films formed at the solid-liquid interface depend on the saliva composition and especially on the physical-chemical characteristics of the substrate (Barrantes, Arnebrant, Lindh, Colloids and Surfaces A: Physicochem Eng Aspects 2014, 442: 56-62). Concerning the composition of saliva, salivary protein profiles are substantially modified by age and diet, which has an impact on the abundance of some proteins (Morzel, Palicki, Chabanet, Lucchi, Ducoroy, Chambon, Nicklaus, ArcH Oral Biol 2011, 56:634-642). However, the aim of our study has been to determine whether hydrogen peroxide treatment affects growth, differentiation and activity of osteoclast-like cells, as well as the putative modulatory action of osteostatin and fibroblast growth factor 2 , in the absence of other protection agents. For all these 
reasons, authors thank the reviewer and will take his(her) suggestions into account for future studies. 


\section{Graphical abstract 1:}

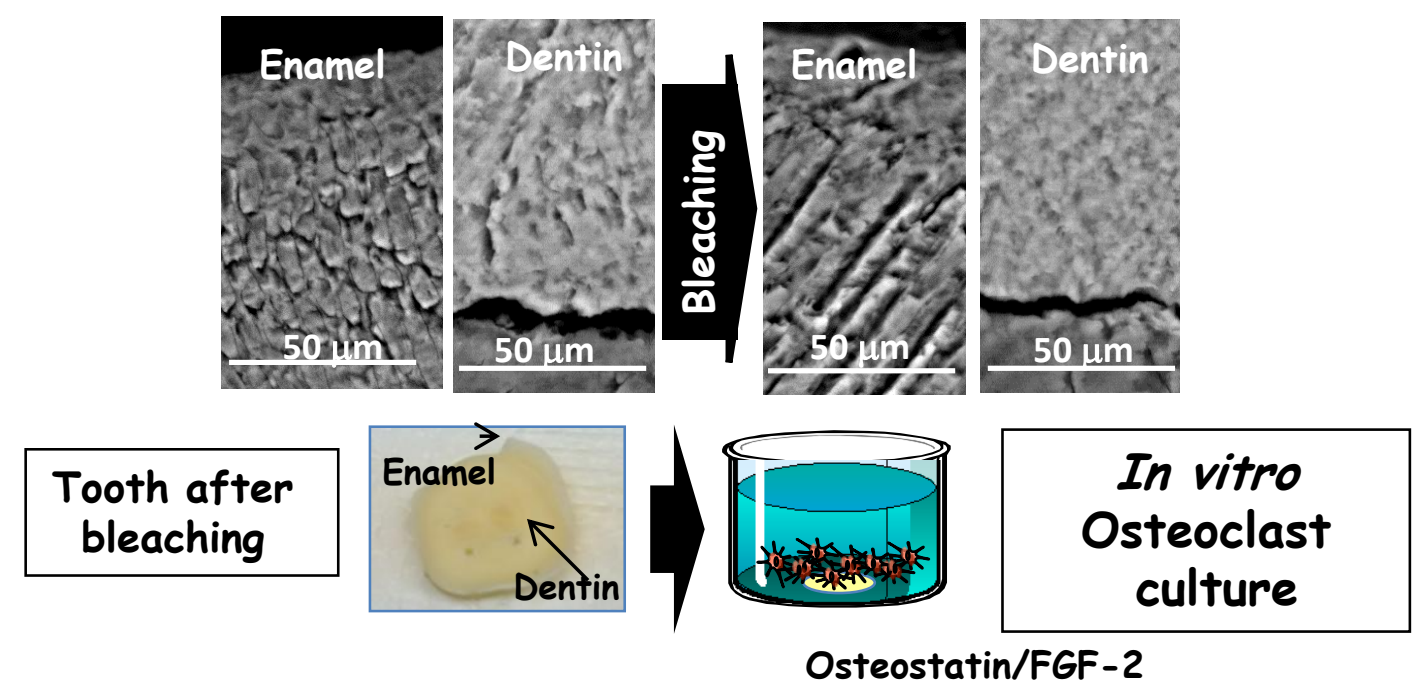




\title{
Effects of bleaching on osteoclast activity and their modulation by osteostatin and fibroblast growth factor 2
}

\author{
Carolina Torres-Rodríguez ${ }^{\mathrm{a}}$, M.Teresa Portolés ${ }^{\mathrm{b}}$, M. Concepción Matesanz ${ }^{\mathrm{b}}$, Javier \\ Linares $^{\mathrm{b}}$, M. José Feito ${ }^{\mathrm{b}}$, Isabel Izquierdo-Barba ${ }^{\mathrm{c}, \mathrm{d}}$, Pedro Esbrit ${ }^{\mathrm{e}}$, María Vallet- \\ $\operatorname{Regí}^{\mathrm{a}, \mathrm{b}^{*}}$
}

${ }^{a}$ Departamento de Salud Oral, Facultad de Odontología, Universidad Nacional de Colombia, Sede Bogotá, Colombia

ctorresr@unal.edu.co

${ }^{\mathrm{b}}$ Departmento de Bioquímica y Biología Molecular I, Facultad de Ciencias Químicas, Universidad Complutense, Madrid, Spain portoles@quim.ucm.es, conchitamatesanz@hotmail.com, javilinares_88@ hotmail.com, mjfeito@pdi.ucm.es

cDepartamento de Química Inorgánica y Bioinorgánica, Facultad de Farmacia, Universidad Complutense de Madrid, Instituto de Investigación Sanitaria Hospital 12 de Octubrei+12, Plaza Ramón y Cajal s/n, 28040 Madrid, Spain ibarba@ucm.es, vallet@ucm.es

${ }^{\mathrm{d}}$ CIBER de Bioingeniería, Biomateriales y Nanomedicina (CIBER-BBN) ibarba@ucm.es, vallet@ucm.es

${ }^{\mathrm{e}}$ Laboratorio de Metabolismo Mineral y Óseo, Instituto de Investigación Sanitaria (IIS)-Fundación Jiménez Díaz, Madrid, Spain

PEsbrit@fjd.es

*Corresponding author: María Vallet-Regí

E-mail address: vallet@ucm.es 


\begin{abstract}
Hypothesis: Dental bleaching with $\mathrm{H}_{2} \mathrm{O}_{2}$ is a common daily practice in dentistry to correct discoloration of anterior teeth. The aim of this study has been to determine whether this treatment of human teeth affects growth, differentiation and activity of osteoclast-like cells, as well as the putative modulatory action of osteostatin and fibroblast growth factor 2 (FGF-2).

Experiments: Previously to the in vitro assays, structural, physical-chemical and morphological features of teeth after bleaching were studied. Osteoclast-like cells were cultured on human dentin disks, pre-treated or not with $38 \% \mathrm{H}_{2} \mathrm{O}_{2}$ bleaching gel, in the presence or absence of osteostatin $(100 \mathrm{nM})$ or FGF-2 $(1 \mathrm{ng} / \mathrm{ml})$. Cell proliferation and viability, intracellular content of reactive oxygen species (ROS), pro-inflammatory cytokine (IL-6 and TNF $\alpha$ ) secretion and resorption activity were evaluated.

Findings: Bleaching treatment failed to affect either the structural or the chemical features of both enamel and dentin, except for slight morphological changes, increased porosity in the most superficial parts (enamel), and a moderate increase in the wettability degree. In this scenario, bleaching produced an increased osteoclast-like cell proliferation but decreased cell viability and cytokine secretion, while it augmented resorption activity on dentin. The presence of either osteostatin or FGF-2 reduced the osteoclast-like cell proliferation induced by bleaching. FGF-2 enhanced ROS content, whereas osteostatin decreased ROS but increased TNF $\alpha$ secretion. The bleaching effect on resorption activity was increased by osteostatin, but this effect was less evident with FGF-2.

Conclusions: These findings further confirm the deleterious effects of tooth bleaching by affecting osteoclast growth and function as well as different modulatory actions of osteostatin and FGF-2.
\end{abstract}

Keyworks: Dental bleaching; external cervical resorption; osteoclast; fibroblast growth factor 2; osteostatin 


\section{Introduction}

Biomineralization is a biological process involving the formation of complex inorganic materials in both prokaryotes and eukaryotes. Hard tissues of mammals mostly result from mineralization of self-assembled organic matrices, where associated water molecules are progressively replaced by mineral. This process depends on the presence of nucleation sites triggering crystal growth that is strictly controlled by ionic and macromolecular crystal growth inhibitors within and outside the organic matrix, respectively (1).

Hard bone tissue can be defined as composite mineral-organic material where parameters such as the mineral/organic ratio, the crystal dimensions, the stoichiometry and the surface properties are rigorously controlled to comply with bone tissue functions (2-4). The organic matrix consists primarily of a fibrous protein, collagen, and lesser amounts of other non-collagenous proteins. In tooth, collagen is also the major organic constituent of dentin and cementum, but there is no collagen in enamel. The addition of mineral to the collagen matrix confers rigidity to bones and teeth and determines their load-bearing capacity. This mineral, referred to as apatite phase, is an analogue of hydroxyapatite and has typically a nanocrystalline structure.

Among the remarkable aspects of mineral apatite are the widely ranging properties and crystal-chemical versatility which translates into functional and biological differences between bone, dentin and enamel. Bone apatite nanocrystals exhibit a variety of substitutions and vacancies that make the $\mathrm{Ca} / \mathrm{P}$ molar ratio distinct from the stoichiometric hydroxyapatite ratio of $1.67(5,6)$. In contrast, enamel apatite has fewer substitutions and higher crystal size than bone or dentin mineral and more closely approximates stoichiometric hydroxyapatite. The common general features of biological apatites and the differences concerning the chemical and the structural characteristics of the mineral apatite in bone and enamel are shown in Fig.1 (at the top and bottom, respectively). In this figure, the average compositions of both hard tissues are also depicted $(7,8)$.

Fig.1 also shows the tooth structure, with its two parts (crown and root) and its different layers: enamel, dentin, pulp and cementum. Loss of dental hard tissue (cementum and dentin) can occur by external cervical resorption (ECR) as a result of odontoclastic action $(9,10)$. Cementum protects the underlying root dentin from being resorbed, but damage of this protective cementum layer below the epithelial attachment 
can expose the root surface to osteoclasts (odontoclasts), which may then resorb the causing histochemical and biochemical alterations in dental tissues by inducing cytotoxic responses (12-14). $\mathrm{H}_{2} \mathrm{O}_{2}$ can diffuse through enamel and dentin, penetrating the pulp chamber through dentinal tubules into the cervical periodontal tissues, where it acts as a strong oxidizing agent, reducing pulp-reparative capacity and leading to tissue necrosis, pulpal pain and ECR $(9,15,16)$. Therefore, the study of the osteoclast behavior after bleaching treatment would be important to understand this superficial oxidative effect on ERC, which mainly depends on various intrinsic factors of the substrate such as surface chemistry, mineralization degree as well as micro-and macroporosity (17).

The central role of fibroblast growth factor (FGF) signaling in mammalian tooth development has been recently reviewed (18). FGF-2 modulates osteoblastic function, induces angiogenesis and promotes osteoblast adhesion, differentiation and proliferation (19). FGF-2 also exerts both direct and indirect effects on osteoclast differentiation and bone resorption $(20,21)$. Also of interest, it has recently been reported that knock-in mice with the mid-region and the C-terminal tail of parathyroid hormone-related protein (PTHrP), an important modulator of bone remodeling, display delayed tooth eruption, malocclusion and discoloration, indicating a mineralization defect; their incisors showing reduced bone area with abundant osteoclast-like cells (22). Several studies also show that the putative C-terminal (107-139) fragment of PTHrP or the shorter peptide PTHrP (107-111) (known as osteostatin) has osteogenic features by direct interaction with osteoblasts $(23,24)$; whereas its effect on osteoclasts appears to depend on the experimental system (25-27).

The aim of this in vitro study was to investigate the effect of bleaching $\left(\mathrm{H}_{2} \mathrm{O}_{2-}\right.$ enriched) on structural and physical-chemical properties of teeth and its impact on osteoclast activity, and the modulatory effect of two known bone cytokines, osteostatin and FGF-2, as putative modulatory factors in this scenario.

\section{Materials and Methods}

\subsection{Preparation of human dentin disks and bleaching treatment}

For this study, third human molars from different subjects aged 18 to 23 years were obtained for orthodontic indication with prior informed consent and informative book. This study protocol was reviewed and approved by the Local Ethics Committee 
of the Faculty of Dentistry at the National University of Colombia. Extraction, disinfection and storage of the samples were carried out according to the Tooth Bank protocol. Tooth specimens were stored in deionized water and subjected to treatment with $38 \% \mathrm{H}_{2} \mathrm{O}_{2}$ bleaching gel for $20 \mathrm{~min}$, and gently rinsed with distilled water thereafter. After bleaching, the teeth were characterized by different techniques to determine the possible structural, morphological and physical-chemical changes derived of such treatment. X-ray powder diffraction (XRD) was performed in a Panalytical Empyrean diffractometer with $\mathrm{Cu}$ tube operated at $40 \mathrm{~mA}$ and $45 \mathrm{kV}$ (28). Environmental scanning electron microscopy (ESEM) was carried out in a FEI QUANTA 200 apparatus at an accelerating voltage of $30 \mathrm{kV}$ and low vacuum $(0.7$ Torr). X-Ray energy dispersive (EDS) spectrometry was performed using an Oxford detector coupled to the ESEM. For these purposes, each whole tooth was cut in two halves at amelocemental junction (longitudinal section) with a diamond blade (Isomet 1000; Buehler, Lake Bluff, IL), allowing the characterization of both enamel and dentin. Moreover, in order to assess the chemical composition of the outermost surface exposed to the treatment (enamel), electron probe microanalyzer (EPMA) studies were performed using a JEOL Superprobe JXA-8900. The analyses were carried out on five whole teeth, which were embedded in resin leaving exposed the enamel surface, and subsequently were coated with graphite. These tooth fragments were analyzed in the same manner after bleaching.

To estimate the wettability of the tooth samples, contact angles were measured on tooth disks (5-6 $\mathrm{mm}$ diameter and $2 \mathrm{~mm}$ thickness) obtained by transversally cutting at the middle third of the crown with a diamond blade mounted in a precision cutting machine (Isomet 1000; Buehler, Lake Bluff, IL). The experiments were performed by using the sessile drop method at $25^{\circ} \mathrm{C}$ on a CAM $200 \mathrm{KSV}$ contact angle goniometer. Pictures of the drops were taken every $1 \mathrm{~s}$. The software delivered by the instrument manufacturer calculated the contact angles on the basis of a numerical solution of the full Young-Laplace equation (29).

\subsection{Osteoclast-like cell cultures}

The in vitro cell evaluation was performed on tooth disks $(5-6 \mathrm{~mm}$ diameter and $2 \mathrm{~mm}$ thickness) containing enamel and dentin obtained as described above. These tooth specimens, denoted as "dentin" (the predominant component) henceforth, were 
sterilized under UV light for $30 \mathrm{~min}$. Disk samples without bleaching treatment were used as controls.

Murine RAW-264.7 macrophages (ATCC, TIB-71) were seeded on bleached or unbleached human dentin disks in 24-well culture dishes (Cultek, Madrid, Spain), at a density of $5 \times 10^{4}$ cells/ml in Dulbecco's Modified Eagle's Medium (DMEM) supplemented with $10 \%$ fetal bovine serum (FBS), $1 \mathrm{mM} \mathrm{L-glutamine,} 200 \mu \mathrm{g} / \mathrm{ml}$ penicillin and $200 \mu \mathrm{g} / \mathrm{ml}$ streptomycin (all products supplied by BioWhittaker, Lonza, Verviers, Belgium). To trigger osteoclast differentiation, $40 \mathrm{ng} / \mathrm{ml}$ recombinant mouse receptor activator of NF- $\kappa$ B ligand (RANKL; BioLegend, San Diego, CA), $25 \mathrm{ng} / \mathrm{ml}$ recombinant mouse macrophage-colony stimulating factor (GM-CSF; Biolegend) and 5 $\mu \mathrm{M}$ mitogen-activated kinase inhibitor U0126 (Enzo Life Sciences, Farmingdale, NY) were added to the culture medium for 7 days. These additions were previously shown to induce RAW-264.7 cells to acquire osteoclastic features $(30,31)$. Some cell cultures were also treated with either $100 \mathrm{nM}$ osteostatin (Bachem, Bubendorf, Switzerland) or 1 ng/ml FGF-2 linked to a Si-HA matrix as described previously (32). Controls without these agents were carried out in parallel. Cells were cultured in a humidified $5 \% \mathrm{CO}_{2}$ atmosphere at $37^{\circ} \mathrm{C}$ for 7 days, renewing culture medium after 3 days. Then, cells were washed with phosphate-buffered saline (PBS), harvested using $1 \mathrm{mM}$ EDTA in PBS at $4^{\circ} \mathrm{C}$ during $10 \mathrm{~min}$ and counted in a Neubauer hemocytometer. Cell suspensions were then centrifuged at 310xg for $10 \mathrm{~min}$ and resuspended in fresh medium for analysis of cell viability and intracellular reactive oxygen species (ROS) content, as described below.

\subsection{Evaluation of cell viability and intracellular ROS content by flow cytometry}

Cell viability was determined by the exclusion of propidium iodide (PI) (SigmaAldrich, St. Louis, MO), at $0.005 \%$ in PBS, which stains DNA in dead cells. PI fluorescence was excited at $488 \mathrm{~nm}$ and the emission was measured at $670 \mathrm{~nm}$ in a FACScalibur Becton Dickinson Flow Cytometer (BD Biosciences, San Jose, CA). To

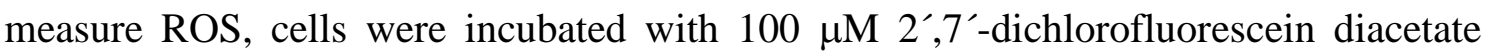
(DCFH-DA; Serva, Heidelberg, Germany) for $30 \mathrm{~min}$ at $37^{\circ} \mathrm{C}$. After probe incorporation, DCF fluorescence was excited by a $15 \mathrm{~mW}$ laser tuning to $488 \mathrm{~nm}$, and measuring emission with a 530/30 band pass filter in the flow cytometer. The conditions for data acquisition and analysis were established using negative and positive controls 
with the CellQuest Program. These conditions were maintained during all the experiments. At least 10,000 cells were analyzed in each sample.

\subsection{Dentin resorption assay}

The capacity of osteoclast-like cells to resorb both types of human dentin disks was also evaluated. RAW-264.7 cells were cultured in osteoclast-differentiation medium with or without the tested agonists for 7 days as described above. Following cell detachment with a cell scraper (Sarsted, Nümbrecht, Germany), the disks were subsequently dehydrated and coated with gold-palladium, and examined with a JEOL JSM-6400 SEM (JEOL Ltd., Tokyo, Japan).

\subsection{Analysis of pro-inflammatory cytokines}

The amount of tumor necrosis factor (TNF) $\alpha$ and interleukin (IL)- 6 in the cellconditioned medium under the different conditions described above was quantified by ELISA (Gen-Probe, Diaclone, BesançonCedex, France), according to the manufacturer's instructions. The sensitivity of these assays was $25 \mathrm{pg} / \mathrm{ml}$ and $10 \mathrm{pg} / \mathrm{ml}$, respectively, and their inter assay variation coefficients were $<10 \%$.

\subsection{Statistics}

Data throughout the text are expressed as mean \pm SD. Statistical analysis was performed using the Statistical Package for the Social Sciences (SPSS) version 19 software. Statistical comparisons among the experimental groups were done by analysis of variance (ANOVA) with post-hoc Scheffé's test. $p<0.05$ was considered significant.

\section{Results and Discussion}

Previously to the in vitro assays, a morphological, structural and physicalchemical characterization of the tooth samples was carried out. Fig.2 shows the tooth bleaching effects on the morphology of human enamel and dentin. SEM micrographs show notable changes concerning the enamel morphology of the bleached-enamel compared with the unbleached sample. Whereas typical enamel structure prism is displayed in the untreated sample (Fig. 2A), after bleaching, this typical morphology was lost, appearing deep longitudinal cavities through the enamel structure (Fig. 2B). This is in agreement with the studies by Hanks et al. (33), showing that bleaching agents 
increased enamel porosity owing to matrix disruption, due to free radical oxidation of its structural components. Furthermore, direct ESEM evaluation of enamel-dentin and dentin zones evidenced morphological changes in the most superficial parts of the enamel without altering the dentin area after bleaching treatment (Fig.2C and D). Fig. 3 and Table 1 summarize the results derived from EDS and EPMA analyses before and after bleaching. The chemical characterization showed no significant variations in the composition in both enamel and dentin zones after bleaching treatment. These results are consistent with XRD analyses (data not shown), which do not support any structural and microstructural change of the apatite phase after this bleaching treatment (28). In fact, XRD studies showed diagrams corresponding to the apatite with profiles "more crystalline" for the enamel part than for dentin whose diagrams were wider and with less-defined peaks. No modifications in the intensity or the position of the peaks were observed after bleaching, indicating that the crystallinity of the apatite remains unaltered in both zones (enamel and dentin). These findings are in agreement with our previous studies, showing that neither the structural nor the chemical features of both enamel and dentin were altered after the same type of bleaching treatment as used here (28).

Table 1: Chemical composition as atomic percent of the different elements obtained by EPMA and EDS analysis.

\begin{tabular}{|c|l|l|l|l|l|l|}
\hline Area/Elements & Ca & P & Mg & Cl & F & Na \\
\hline \multicolumn{7}{|c|}{ EPMA* } \\
\hline Enamel Unbleached & $61.0 \pm 3.0$ & $35.7 \pm 2.7$ & $0.6 \pm 0.2$ & $1.25 \pm 0.7$ & $0.63 \pm 0.3$ & $0.82 \pm 0.8$ \\
\hline Enamel $_{\text {Bleached }}$ & $61.0 \pm 3.5$ & $35.0 \pm 2.6$ & $0.7 \pm 0.3$ & $1.14 \pm 0.8$ & $0.70 \pm 0.5$ & $1.40 \pm 0.7$ \\
\hline \multicolumn{7}{|c|}{ EDS } \\
\hline Enamel $_{\text {Unbleached }}$ & $60.4 \pm 2.3$ & $37.5 \pm 1.8$ & $0.5 \pm 0.2$ & $1.2 \pm 0.3$ & - & $1.0 \pm 0.5$ \\
\hline Enamel $_{\text {Bleached }}$ & $60.6 \pm 2.1$ & $36.8 \pm 1.1$ & $0.7 \pm 0.3$ & $1.3 \pm 0.3$ & - & $1.2 \pm 0.5$ \\
\hline Dentin $_{\text {Unbleached }}$ & $61.4 \pm 2.0$ & $35.9 \pm 2.0$ & $0.5 \pm 0.3$ & $1.3 \pm 0.7$ & - & $2.3 \pm 0.6$ \\
\hline Dentin $_{\text {Bleached }}$ & $62.5 \pm 2.0$ & $35.4 \pm 2.0$ & $0.8 \pm 0.5$ & $1.1 \pm 0.8$ & - & $2.2 \pm 0.6$ \\
\hline
\end{tabular}

* Note that this was conducted in the most external surface of the enamel. Only small traces of fluorine were observed in the outermost surface of the teeth.

Data are mean \pm SD of 15 determinations performed in different areas of five different tooth specimens. 
Fig. 4 shows the micrographs of the sessile water drops onto the surfaces of tooth before and after treatment. The initial contact angles, measured one second after water drop deposition, were $65^{\circ}$ and $40^{\circ}$ for unbleached and bleached tooth, demonstrating a slight increase of the wettability, which could be ascribed to the increase of porosity after bleaching.

In the present study, we found that the number of RAW-264.7 cells grown on bleached human dentin was higher than that on unbleached dentin. The presence of either osteostatin or FGF-2 showed a similar tendency to normalize these increased values (not shown). On the other hand, cells cultured on bleached dentin disks showed a moderate but significant decrease (about 30\%) in cell viability in comparison to unbleached controls (showing on average $80 \%$ viability). This action was mimicked by FGF-2 but prevented by osteostatin which similarly increased cell viability in both types of dentin studied (not shown). The bleaching pre-treatment failed to significantly affect the intracellular cell content of ROS at the end of the study. However, FGF-2 enhanced this content whereas osteostatin decreased ROS even in control cells grown on unbleached dentin (Fig.5A). Thus, it appears that ROS production is independent of bleaching, and osteostatin or FGF-2 in fact may have effects independent of bleaching on these cells. Secretion of IL-6 was dramatically decreased in these osteoclast-like cells maintained on bleaching pre-treated dentin, with or without addition of FGF-2 or osteostatin (Fig.5B). TNF $\alpha$ secretion by these cells was also decreased in this bleaching environment, but this was compensated for by osteostatin, which per se dramatically stimulated the secretion of this cytokine in cell cultures on unbleached dentin (Fig.5C).

The capacity of RAW-264.7 cells cultured in the experimental conditions described above to resorb both types of dentin studied was next examined by SEM. We found different patterns of pits produced by these cells on dentin depending on the different experimental settings. As shown in Fig.6, the resorption areas observed on 
bleaching-treated dentin had a larger diameter that on untreated control dentin. This mentioned above, in these cell cultures, osteostatin increased the secretion of TNF $\alpha$, an osteoclastogenesis inducer (34), but in larger quantities in the unbleached samples compared to bleached samples. Thus, it is unlikely that overexpression of this cytokine might be responsible for the higher resorption activity of RAW-264.7 cells on dentin induced by osteostatin in this situation. It is also pertinent to mention that the effects of FGF-2 on osteoclast formation and bone resorption appear to be complex ant not completely elucidated. Thus, this growth factor has been shown to promote the fusion of osteoclast precursors into giant cells and to trigger mature osteoclasts to reorganize their actin cytoskeleton. However, FGF-2 strongly inhibits the pro-resorptive activities of calcitriol (20).

\section{Conclusions}

A short exposure of human molar teeth to $38 \% \mathrm{H}_{2} \mathrm{O}_{2}$ causes slight morphological changes in the most superficial parts (enamel), moderately increasing the porosity as well as the wettability degree. However, neither the structural nor the chemical features of both enamel and dentin were altered by this treatment. In this scenario, bleaching generates favorable surface to promote proliferation and proresorptive activity of osteoclast-like cells. The presence of either osteostatin or FGF-2 reduced this effect of bleaching on osteoclast-like cell proliferation. On the other hand, the bleaching effect on osteoclast resorption activity was increased by osteostatin, although this effect was less evident with FGF-2. These findings further confirm the disadvantages of tooth bleaching by targeting osteoclast growth and function, and indicate different modulatory actions of osteostatin and FGF-2.

\section{Acknowledgements}

The authors deny any conflicts of interest. This study was supported by research grants from the Spanish Ministerio de Ciencia e Innovación (MAT2012-35556), Ministerio de Economía y Competitividad (MAT2013-43299-R), Instituto de Salud Carlos III (PIE13/00051) and Agening Network of Excellence (CSO2010-11384-E). The authors 
thank the technical support of the staff of the ICTS National Center for Electron Microscopy and CAI of Cytometry and Fluorescence Microscopy Center, UCM, Madrid. M.C. Matesanz and J. Linares are greatly indebted to MICINN and CIBER$\mathrm{BBN}$, respectively, for predoctoral fellowships.

\section{References}

1. GlimcherMJ.Role of collagen fibrils and collagen-phosphoprotein complexes in vitro and in vivo.Anat $\operatorname{Rec} 1989 ; 224: 139-53$.

2. Mann S. Molecular recognition in biomineralization. Nature 1988;332:119-24.

3. McKee MD, Addison WN, Kaartinen MT. Hierarchies of extracellular matrix and mineral organization in bone of the craniofacial complex and skeleton. Cells Tissues Organs 2005;181:76-188.

4. Vallet-Regí M, Arcos D. Biomimetic Nanoceramics in Clinical Use: From Materials to Applications. Cambridge, UK: RSC Pub; 2008.

5. Vallet-Regí M, González-Calbet JM. Calcium phosphates as substitution of bone tissues. Prog Solid State Chem2004;32:1-31.

6. Boskey AL. Assessment of bone mineral and matrix using backscatter electron imaging and FTIR imaging. Current Osteoporosis Reports 2006;4:71-5.

7. Cazalbou S, Combes C, Eichert D, Rey C. Adaptativephysico-chemistry of biorelated calcium phosphates. J Mater Chem 2004;14:2148-53.

8. Pasteris JD, Wopenka B, Valsami-Jone E. Bone and Tooth Mineralization: Why Apatite? Elements 2008;4:97-104.

9. Patel S, Kanagasingam S, Pitt FT. External cervical resorption: A review. J Endod 2009;35:616-25.

10. Zhou YZ, Cao Y, Liu W, Chu C-H, Li Q-L. Polydopamine-induced tooth remineralization. ACS Appl Mater Interfaces. 2012;4:6901-10.

11. Gold SI, Hasselgren G. Peripheral inflamatory root resorption: a review of the literature with case reports. J ClinPeriodontol. 1992;19:523-34.

12. Madison S, Walton R. Cervical root resorption following bleaching of endodontically treated teeth. J Endod 1990;16:570-4.

13. Toledano M, Yamauti M, Osorio E, Osorio R. Bleaching agents increase metalloproteinases mediated collagen degradation in dentin. $\mathbf{J}$ Endod 2011;37:1668-72. 
14. Eimar H, Siciliano R, Abdallah MN, Nader SA, Amin WM, Martínez PP, Celemin A, Cerruti M, Tamimi F. Hydrogen peroxide whitens teeth by oxidizing the organic structure. J Dent 2012; 40:25-33.

15. Camargo SEA, Valera MC, Camargo CHR, Mancini MNG, Menezes MM. Penetration of $38 \%$ hydrogen peroxide into the pulp chamber in bovine and human teeth submitted to office bleach technique. J Endod 2007;33:1074-1077.

16. Bonafé E, Bacovis CL, Iensen S, Loguercio AD, Reis A, Kossatz S. Tooth sensitivity and efficacy of in-office bleaching in restored teeth. J Dent 2013; 41:363-369.

17. Badran Z, Pilet P, Verron E, Bouler J-M, Weiss P, Grimandi G, Guicheux J, Soueidan A. Assay of in vitro osteoclast activity on dentine, and synthetic calcium phosphate bone substitutes. J Mater Sci: Mater Med 2012;23:797-803.

18. Li C-Y, Prochazka J, Goodwin AF, Klein OD. Fibroblast growth factor signaling in mammalian tooth development. Odontology 2014; 102:1-13.

19. Lozano D, Feito MJ, Portal-Núñez S, Lozano RM, Matesanz MC, Serrano MC, Vallet-Regí M, Portolés MT, Esbrit P. Osteostatin improve the osteogenic activity of fibroblast growth factor 2 inmobilized in Si-dopped hydroxyapatite in osteoblastic cells. ActaBiomater 2012; 8:2770-7.

20. Zuo J, Jiang J, Dolce C, Holliday LS. Effects of basic fibroblast growth factor on osteoclasts and osteoclast-like cells. Biochem Biophys Res Comm 2004; 318:162-7.

21. Lu X, Su N, Yang J, Huang W, Li C, Zhao L, He Q, Du X, Shen Y, Chen B, Chen L. Fibroblast growth factor receptor 1 regulates the differentiation and activation of osteoclasts through Erk1/2 pathway. BiochemBiophys Res Comm 2009; 390:494-9.

22. Toribio RE, Brown HA, Novince CM, Marlow B, Hernon K, Lanigan LG, Hildreth BE 3rd, Werbeck JL, Shu ST, Lorch G, Carlton M, Foley J, Boyaka P, McCauley LK, Rosol TJ. The midregion, nuclear localization sequence, and C terminus of PTHrP regulate skeletal development, hematopoiesis, and survival in mice. FASEB J 2010; 24:1947-57.

23. Cornish J, Callon KE, Lin C, Xiao C, Moseley JM, Reid IR. Stimulation of osteoblast proliferation by C-terminal fragments of parathyroid hormone-related protein. J Bone Miner Res 1999;14:915-22. 
24. Lozano D, Manzano M, Doadrio JC, Salinas AJ, Vallet-Regí M, GómezBarrena E, Esbrit P. Osteostatin-loaded bioceramics stimulate osteoblastic growth and differentiation. Acta Biomater 2010; 6:797-803.

25. Fenton AJ, Kemp BE, Kent GN, Moseley JM, Zheng MH, Rowe DJ, Britto JM, Martin TJ, Nicholson GC. A carboxyl-terminal peptide from the parathyroid hormone-related protein inhibits bone resorption by osteoclasts. Endocrinology 1991;129:1762-68.

26. Cornish J, Callon KE, Nicholson GC, Reid IR. Parathyroid hormone-related protein-(107-139) inhibits bone resorption in vivo. Endocrinology 1997;38: 1299-304.

27. Kaji H, Sugimoto T, Kanatani M, Fukase M, Chihara K. Carboxyl-terminal peptides from parathyroid hormone-related protein stimulate osteoclast-like cell formation. Endocrinology 1995; 136:842-8.

28. Izquierdo-Barba I, Torres-Rodríguez C, Matesanz E, Vallet-Regí M. New approach to determine the morphological and structural changes in the enamel as consequence of dental bleaching. Materials Letters, 2015;14:302-306.

29. Bracco G, Holst B. Surface Science Techniques, Springer Series in Surface Sciences 51, Editorial Springer-Verlag Berlin Heidelberg 2013. DOI: 10.1007/978-3-642-34243-1_1.

30. Hotokezaka H, Sakai E, Kanaoka K, Saito K, Matsuo K, Kitaura H, Yoshida N, Nakayama K. U0126 and PD98059, specific inhibitors of MEK, accelerate differentiation of RAW264.7 cells into osteoclast-like cells. J BiolChem 2002; 277:47366-72.

31. Matesanz MC, Linares J, Lilue I, Sánchez-Salcedo S, Feito MJ, Arcos D, Vallet-Regí M, Portolés MT. Nanocrystalline silicon substituted hydroxyapatite effects on osteoclast differentiation and resorptive activity. J Mater Chem B $2014 ; 2: 2910-19$.

32. Feito MJ, Lozano RM, Alcaide M, Ramírez-Santillán C, Arcos D, Vallet-Regí M, PortolésMT.Immobilization and bioactivity evaluation of FGF-1 and FGF-2 on powdered silicon-doped hydroxyapatite and their scaffolds for bone tissue engineering. J Mater Sci Mater Med 2011; 22:405-16.

33. Hanks CT, Fat JC, Wataha JC, Corcoran JF. Cytotoxicity and dentin permeability of carbamide peroxide and hydrogen-peroxide vital bleaching materials, in vitro. J Dent Res 1993;72:931-8. 
34. Kitaura H, Nagata N, Fujimura Y, Hotokezaka H, Tatamiya M, Nakao N, Yoshida N, Nakayama K. Interleukin-4 directly inhibits tumor necrosis factor$\alpha$-mediated osteoclast formation in mouse bone marrow macrophages. Immunol. Lett. 2003;88:193-9. 


\section{Figure captions}

Fig. 1. Biological apatites are components of both bone and tooth enamel. (Left) A representative long bone (femur; whole tissue), an XRD diagram and scanning electron micrograph of the trabecular bone area are shown. (Right) This shows a cross section of human molar structure (whole tissue), an XRD diagram corresponding to enamel showing higher crystallinity of apatite phase than in bone, and scanning electron micrograph showing the typical enamel structure prisms (8).

Fig. 2. Representative ESEM micrographs of corresponding to tooth enamel and dentin zones before and after bleaching treatment, respectively.

Fig. 3. EDS analysis corresponding to both enamel and dentin areas before and after tooth bleaching. The different locations analyzed are depicted as pink points in the corresponding SEM micrographs.

Fig. 4. Evaluation of surface wettability. Representative micrographs of a water drop onto either an unbleached tooth (left) or a bleached tooth (right) are shown.

Fig. 5. Effects of osteostatinand FGF-2 onintracellular reactive oxygen (ROS) content (A) and IL-6 (B) and TNF $\alpha$ secretion (C), in osteoclast-like cells cultured on bleached dentin (B) or unbleached dentin (UB). Controlswithoutosteostatinor FGF-2 werecarriedout in parallel. Data are expressed as means \pm SD. All the experiments were performed twice and carried out in triplicate. Statistical significance: $* p<0.05$, $* * \mathrm{p}<0.01, * * * \mathrm{p}<0.005$ (compared to control without osteostatin or FGF) and $\# \mathrm{p}<0.05$, $\# \# \mathrm{p}<0.01, \# \# \mathrm{p}<0.005$ (compared to unbleached dentin, UB).

Fig. 6. Representative SEM images of unbleached (UB) or bleached (B) dentin surfaces after culture of RAW-264.7 cells in osteoclast differentiation medium in the absence or presence of either osteostatin or FGF-2. Representative diameters of resorption lacunae are shown in each case. 


\section{Figures}

Fig. 1:
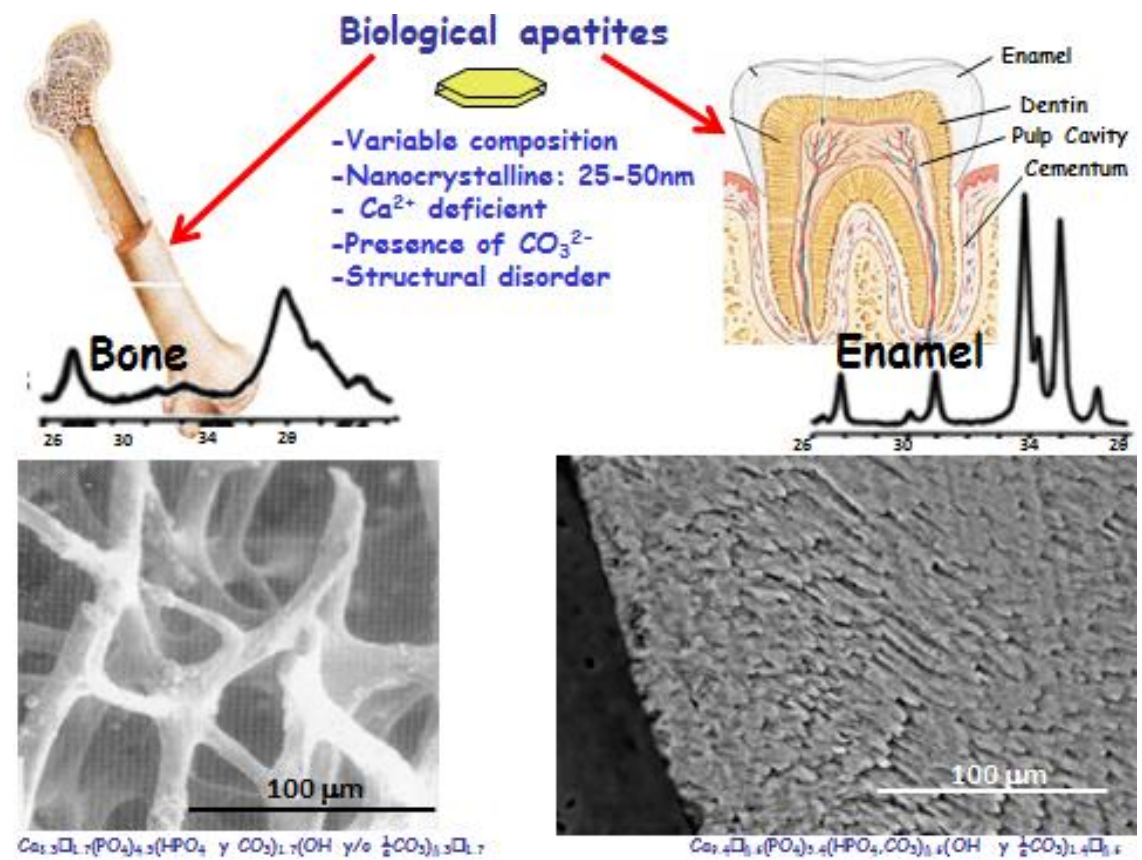

Fig. 2:

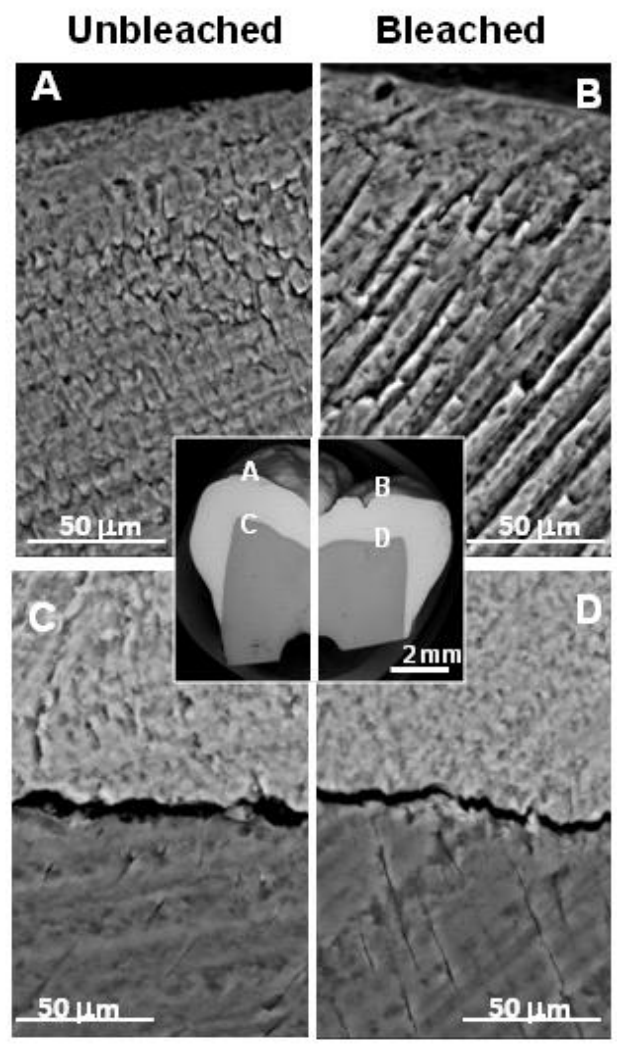


Fig. 3:

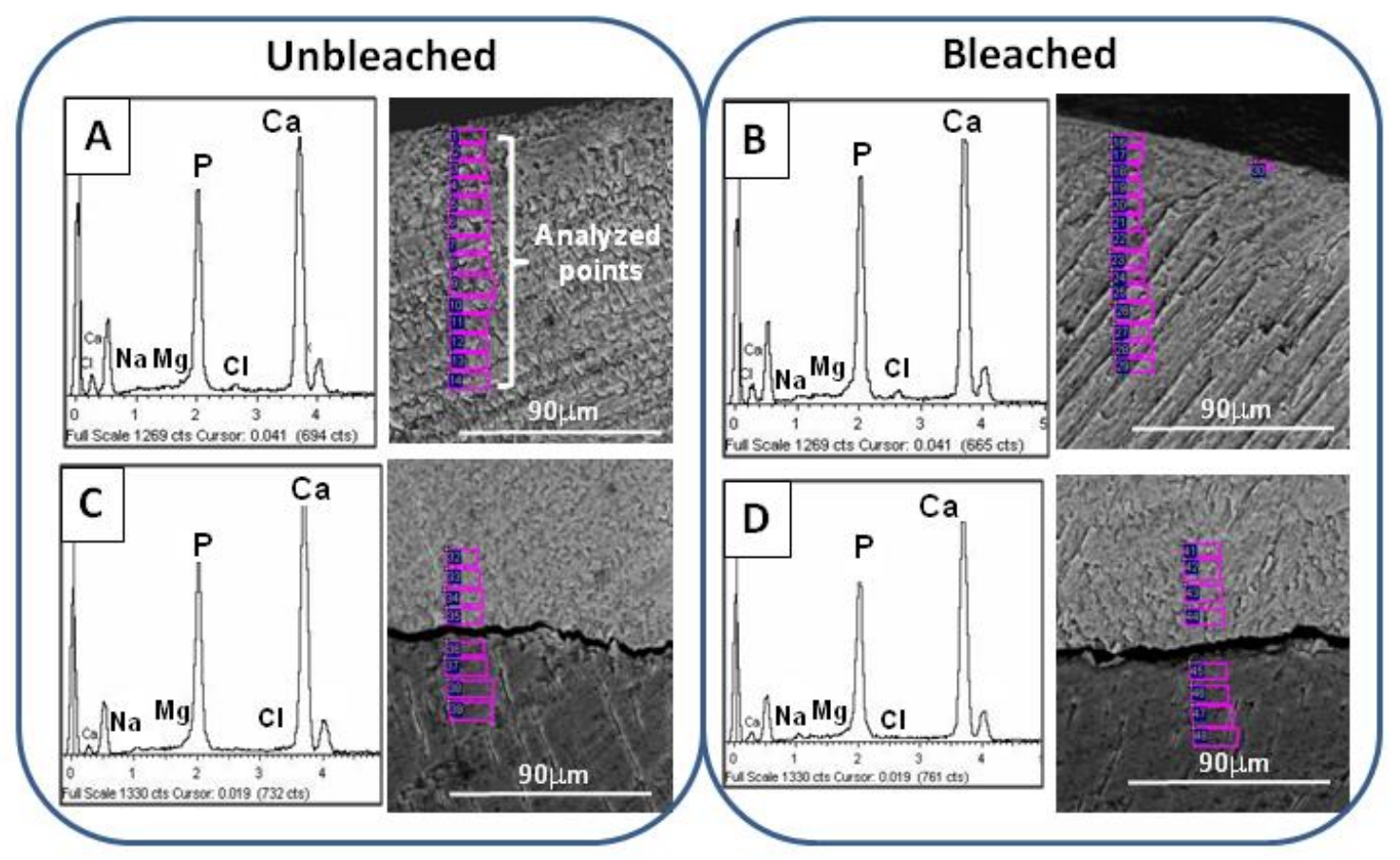

Fig. 4:
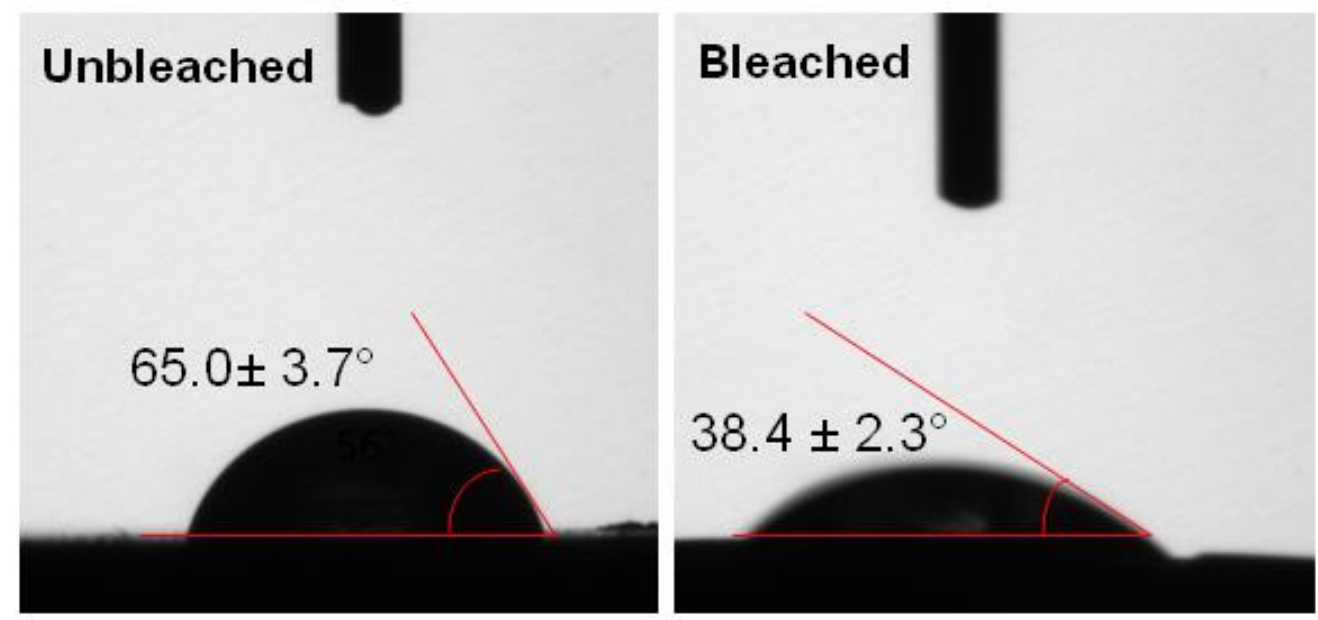
Fig. 5:
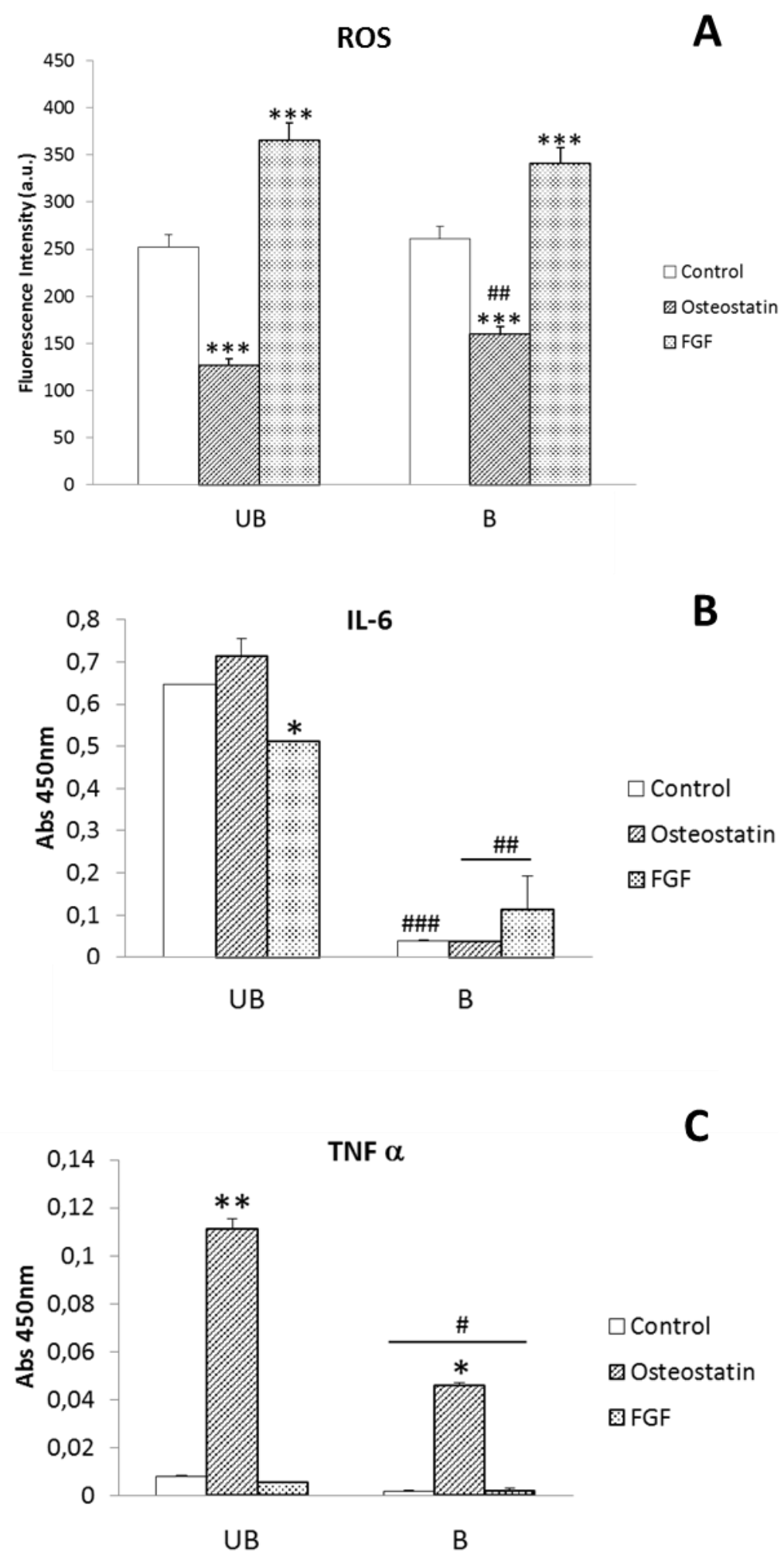
Fig. 6:

1
2
3
3
4
5
6
7
7
8
9
10
11
12
13
14
15
16
17
17
18
19
29
21
21
22
23
24
25
26
27
27
28
29
39
39
31
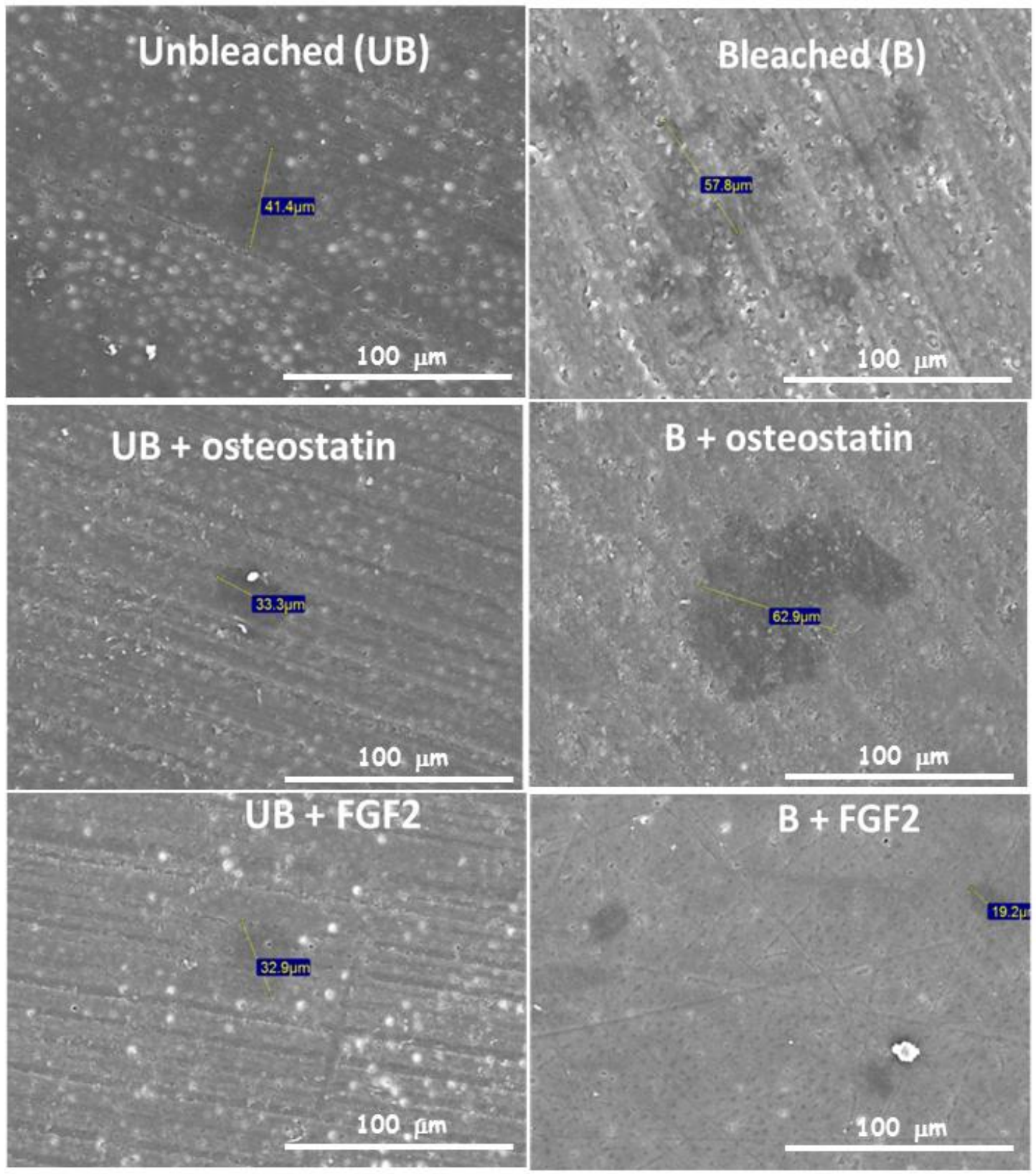

45

48

49

50

51

54

55

56

60 


\title{
Effects of bleaching on osteoclast activity and their modulation by osteostatin and fibroblast growth factor 2
}

\author{
Carolina Torres-Rodríguez ${ }^{\mathrm{a}}$, M.Teresa Portolés ${ }^{\mathrm{b}}$, M. Concepción Matesanz ${ }^{\mathrm{b}}$, Javier \\ Linares $^{\mathrm{b}}$, M. José Feito ${ }^{\mathrm{b}}$, Isabel Izquierdo-Barba ${ }^{\mathrm{c}, \mathrm{d}}$, Pedro Esbrit ${ }^{\mathrm{e}}$, María Vallet- \\ $\operatorname{Regí}^{\mathrm{a}, \mathrm{b}^{*}}$
}

${ }^{a}$ Departamento de Salud Oral, Facultad de Odontología, Universidad Nacional de Colombia, Sede Bogotá, Colombia

ctorresr@unal.edu.co

${ }^{\mathrm{b}}$ Departmento de Bioquímica y Biología Molecular I, Facultad de Ciencias Químicas, Universidad Complutense, Madrid, Spain portoles@quim.ucm.es, conchitamatesanz@hotmail.com, javilinares_88@ hotmail.com, mjfeito@pdi.ucm.es

cDepartamento de Química Inorgánica y Bioinorgánica, Facultad de Farmacia, Universidad Complutense de Madrid, Instituto de Investigación Sanitaria Hospital 12 de Octubrei+12, Plaza Ramón y Cajal s/n, 28040 Madrid, Spain ibarba@ucm.es, vallet@ucm.es

${ }^{\mathrm{d}}$ CIBER de Bioingeniería, Biomateriales y Nanomedicina (CIBER-BBN) ibarba@ucm.es, vallet@ucm.es

${ }^{\mathrm{e}}$ Laboratorio de Metabolismo Mineral y Óseo, Instituto de Investigación Sanitaria (IIS)-Fundación Jiménez Díaz, Madrid, Spain

PEsbrit@fjd.es

*Corresponding author: María Vallet-Regí

E-mail address: vallet@ucm.es 


\begin{abstract}
Hypothesis: Dental bleaching with $\mathrm{H}_{2} \mathrm{O}_{2}$ is a common daily practice in dentistry to correct discoloration of anterior teeth. The aim of this study has been to determine whether this treatment of human teeth affects growth, differentiation and activity of osteoclast-like cells, as well as the putative modulatory action of osteostatin and fibroblast growth factor 2 (FGF-2).

Experiments: Previously to the in vitro assays, structural, physical-chemical and morphological features of teeth after bleaching were studied. Osteoclast-like cells were cultured on human dentin disks, pre-treated or not with $38 \% \mathrm{H}_{2} \mathrm{O}_{2}$ bleaching gel, in the presence or absence of osteostatin $(100 \mathrm{nM})$ or FGF-2 $(1 \mathrm{ng} / \mathrm{ml})$. Cell proliferation and viability, intracellular content of reactive oxygen species (ROS), pro-inflammatory cytokine (IL-6 and TNF $\alpha$ ) secretion and resorption activity were evaluated.

Findings: Bleaching treatment failed to affect either the structural or the chemical features of both enamel and dentin, except for slight morphological changes, increased porosity in the most superficial parts (enamel), and a moderate increase in the wettability degree. In this scenario, bleaching produced an increased osteoclast-like cell proliferation but decreased cell viability and cytokine secretion, while it augmented resorption activity on dentin. The presence of either osteostatin or FGF-2 reduced the osteoclast-like cell proliferation induced by bleaching. FGF-2 enhanced ROS content, whereas osteostatin decreased ROS but increased TNF $\alpha$ secretion. The bleaching effect on resorption activity was increased by osteostatin, but this effect was less evident with FGF-2.

Conclusions: These findings further confirm the deleterious effects of tooth bleaching by affecting osteoclast growth and function as well as different modulatory actions of osteostatin and FGF-2.
\end{abstract}

Keyworks: Dental bleaching; external cervical resorption; osteoclast; fibroblast growth factor 2; osteostatin 


\section{Introduction}

Biomineralization is a biological process involving the formation of complex inorganic materials in both prokaryotes and eukaryotes. Hard tissues of mammals mostly result from mineralization of self-assembled organic matrices, where associated water molecules are progressively replaced by mineral. This process depends on the presence of nucleation sites triggering crystal growth that is strictly controlled by ionic and macromolecular crystal growth inhibitors within and outside the organic matrix, respectively (1).

Hard bone tissue can be defined as composite mineral-organic material where parameters such as the mineral/organic ratio, the crystal dimensions, the stoichiometry and the surface properties are rigorously controlled to comply with bone tissue functions (2-4). The organic matrix consists primarily of a fibrous protein, collagen, and lesser amounts of other non-collagenous proteins. In tooth, collagen is also the major organic constituent of dentin and cementum, but there is no collagen in enamel. The addition of mineral to the collagen matrix confers rigidity to bones and teeth and determines their load-bearing capacity. This mineral, referred to as apatite phase, is an analogue of hydroxyapatite and has typically a nanocrystalline structure.

Among the remarkable aspects of mineral apatite are the widely ranging properties and crystal-chemical versatility which translates into functional and biological differences between bone, dentin and enamel. Bone apatite nanocrystals exhibit a variety of substitutions and vacancies that make the $\mathrm{Ca} / \mathrm{P}$ molar ratio distinct from the stoichiometric hydroxyapatite ratio of $1.67(5,6)$. In contrast, enamel apatite has fewer substitutions and higher crystal size than bone or dentin mineral and more closely approximates stoichiometric hydroxyapatite. The common general features of biological apatites and the differences concerning the chemical and the structural characteristics of the mineral apatite in bone and enamel are shown in Fig.1 (at the top and bottom, respectively). In this figure, the average compositions of both hard tissues are also depicted $(7,8)$.

Fig.1 also shows the tooth structure, with its two parts (crown and root) and its different layers: enamel, dentin, pulp and cementum. Loss of dental hard tissue (cementum and dentin) can occur by external cervical resorption (ECR) as a result of odontoclastic action $(9,10)$. Cementum protects the underlying root dentin from being resorbed, but damage of this protective cementum layer below the epithelial attachment 
can expose the root surface to osteoclasts (odontoclasts), which may then resorb the causing histochemical and biochemical alterations in dental tissues by inducing cytotoxic responses (12-14). $\mathrm{H}_{2} \mathrm{O}_{2}$ can diffuse through enamel and dentin, penetrating the pulp chamber through dentinal tubules into the cervical periodontal tissues, where it acts as a strong oxidizing agent, reducing pulp-reparative capacity and leading to tissue necrosis, pulpal pain and ECR $(9,15,16)$. Therefore, the study of the osteoclast behavior after bleaching treatment would be important to understand this superficial oxidative effect on ERC, which mainly depends on various intrinsic factors of the substrate such as surface chemistry, mineralization degree as well as micro-and macroporosity (17).

The central role of fibroblast growth factor (FGF) signaling in mammalian tooth development has been recently reviewed (18). FGF-2 modulates osteoblastic function, induces angiogenesis and promotes osteoblast adhesion, differentiation and proliferation (19). FGF-2 also exerts both direct and indirect effects on osteoclast differentiation and bone resorption $(20,21)$. Also of interest, it has recently been reported that knock-in mice with the mid-region and the C-terminal tail of parathyroid hormone-related protein (PTHrP), an important modulator of bone remodeling, display delayed tooth eruption, malocclusion and discoloration, indicating a mineralization defect; their incisors showing reduced bone area with abundant osteoclast-like cells (22). Several studies also show that the putative C-terminal (107-139) fragment of PTHrP or the shorter peptide PTHrP (107-111) (known as osteostatin) has osteogenic features by direct interaction with osteoblasts $(23,24)$; whereas its effect on osteoclasts appears to depend on the experimental system (25-27).

The aim of this in vitro study was to investigate the effect of bleaching $\left(\mathrm{H}_{2} \mathrm{O}_{2}\right.$ enriched) on structural and physical-chemical properties of teeth and its impact on osteoclast activity, and the modulatory effect of two known bone cytokines, osteostatin and FGF-2, as putative modulatory factors in this scenario.

\section{Materials and Methods}

\subsection{Preparation of human dentin disks and bleaching treatment}

For this study, third human molars from different subjects aged 18 to 23 years were obtained for orthodontic indication with prior informed consent and informative book. This study protocol was reviewed and approved by the Local Ethics Committee 
of the Faculty of Dentistry at the National University of Colombia. Extraction, protocol. Tooth specimens were stored in deionized water and subjected to treatment with $38 \% \mathrm{H}_{2} \mathrm{O}_{2}$ bleaching gel for $20 \mathrm{~min}$, and gently rinsed with distilled water thereafter. After bleaching, the teeth were characterized by different techniques to determine the possible structural, morphological and physical-chemical changes derived of such treatment. X-ray powder diffraction (XRD) was performed in a Panalytical Empyrean diffractometer with $\mathrm{Cu}$ tube operated at $40 \mathrm{~mA}$ and $45 \mathrm{kV}$ (28). Environmental scanning electron microscopy (ESEM) was carried out in a FEI QUANTA 200 apparatus at an accelerating voltage of $30 \mathrm{kV}$ and low vacuum (0.7 Torr). X-Ray energy dispersive (EDS) spectrometry was performed using an Oxford detector coupled to the ESEM. For these purposes, each whole tooth was cut in two halves at amelocemental junction (longitudinal section) with a diamond blade (Isomet 1000; Buehler, Lake Bluff, IL), allowing the characterization of both enamel and dentin. Moreover, in order to assess the chemical composition of the outermost surface exposed to the treatment (enamel), electron probe microanalyzer (EPMA) studies were performed using a JEOL Superprobe JXA-8900. The analyses were carried out on five whole teeth, which were embedded in resin leaving exposed the enamel surface, and subsequently were coated with graphite. These tooth fragments were analyzed in the same manner after bleaching.

To estimate the wettability of the tooth samples, contact angles were measured on tooth disks (5-6 mm diameter and $2 \mathrm{~mm}$ thickness) obtained by transversally cutting at the middle third of the crown with a diamond blade mounted in a precision cutting machine (Isomet 1000; Buehler, Lake Bluff, IL). The experiments were performed by using the sessile drop method at $25^{\circ} \mathrm{C}$ on a CAM $200 \mathrm{KSV}$ contact angle goniometer. Pictures of the drops were taken every $1 \mathrm{~s}$. The software delivered by the instrument manufacturer calculated the contact angles on the basis of a numerical solution of the full Young-Laplace equation (29).

\subsection{Osteoclast-like cell cultures}

The in vitro cell evaluation was performed on tooth disks (5-6 mm diameter and $2 \mathrm{~mm}$ thickness) containing enamel and dentin obtained as described above. These tooth specimens, denoted as "dentin" (the predominant component) henceforth, were 
sterilized under UV light for $30 \mathrm{~min}$. Disk samples without bleaching treatment were used as controls.

Murine RAW-264.7 macrophages (ATCC, TIB-71) were seeded on bleached or unbleached human dentin disks in 24-well culture dishes (Cultek, Madrid, Spain), at a density of $5 \times 10^{4}$ cells/ml in Dulbecco's Modified Eagle's Medium (DMEM) supplemented with $10 \%$ fetal bovine serum (FBS), $1 \mathrm{mM} \mathrm{L-glutamine,} 200 \mu \mathrm{g} / \mathrm{ml}$ penicillin and $200 \mu \mathrm{g} / \mathrm{ml}$ streptomycin (all products supplied by BioWhittaker, Lonza, Verviers, Belgium). To trigger osteoclast differentiation, $40 \mathrm{ng} / \mathrm{ml}$ recombinant mouse receptor activator of NF- $\kappa$ B ligand (RANKL; BioLegend, San Diego, CA), $25 \mathrm{ng} / \mathrm{ml}$ recombinant mouse macrophage-colony stimulating factor (GM-CSF; Biolegend) and 5 $\mu \mathrm{M}$ mitogen-activated kinase inhibitor U0126 (Enzo Life Sciences, Farmingdale, NY) were added to the culture medium for 7 days. These additions were previously shown to induce RAW-264.7 cells to acquire osteoclastic features $(30,31)$. Some cell cultures were also treated with either $100 \mathrm{nM}$ osteostatin (Bachem, Bubendorf, Switzerland) or 1 ng/ml FGF-2 linked to a Si-HA matrix as described previously (32). Controls without these agents were carried out in parallel. Cells were cultured in a humidified $5 \% \mathrm{CO}_{2}$ atmosphere at $37^{\circ} \mathrm{C}$ for 7 days, renewing culture medium after 3 days. Then, cells were washed with phosphate-buffered saline (PBS), harvested using $1 \mathrm{mM}$ EDTA in PBS at $4^{\circ} \mathrm{C}$ during $10 \mathrm{~min}$ and counted in a Neubauer hemocytometer. Cell suspensions were then centrifuged at $310 \mathrm{xg}$ for $10 \mathrm{~min}$ and resuspended in fresh medium for analysis of cell viability and intracellular reactive oxygen species (ROS) content, as described below.

\subsection{Evaluation of cell viability and intracellular ROS content by flow cytometry}

Cell viability was determined by the exclusion of propidium iodide (PI) (SigmaAldrich, St. Louis, MO), at $0.005 \%$ in PBS, which stains DNA in dead cells. PI fluorescence was excited at $488 \mathrm{~nm}$ and the emission was measured at $670 \mathrm{~nm}$ in a FACScalibur Becton Dickinson Flow Cytometer (BD Biosciences, San Jose, CA). To

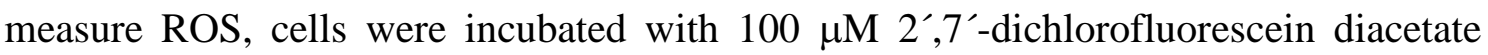
(DCFH-DA; Serva, Heidelberg, Germany) for $30 \mathrm{~min}$ at $37^{\circ} \mathrm{C}$. After probe incorporation, DCF fluorescence was excited by a $15 \mathrm{~mW}$ laser tuning to $488 \mathrm{~nm}$, and measuring emission with a 530/30 band pass filter in the flow cytometer. The conditions for data acquisition and analysis were established using negative and positive controls 
with the CellQuest Program. These conditions were maintained during all the experiments. At least 10,000 cells were analyzed in each sample.

\subsection{Dentin resorption assay}

The capacity of osteoclast-like cells to resorb both types of human dentin disks was also evaluated. RAW-264.7 cells were cultured in osteoclast-differentiation medium with or without the tested agonists for 7 days as described above. Following cell detachment with a cell scraper (Sarsted, Nümbrecht, Germany), the disks were subsequently dehydrated and coated with gold-palladium, and examined with a JEOL JSM-6400 SEM (JEOL Ltd., Tokyo, Japan).

\subsection{Analysis of pro-inflammatory cytokines}

The amount of tumor necrosis factor (TNF) $\alpha$ and interleukin (IL)- 6 in the cellconditioned medium under the different conditions described above was quantified by ELISA (Gen-Probe, Diaclone, BesançonCedex, France), according to the manufacturer's instructions. The sensitivity of these assays was $25 \mathrm{pg} / \mathrm{ml}$ and $10 \mathrm{pg} / \mathrm{ml}$, respectively, and their inter assay variation coefficients were $<10 \%$.

\subsection{Statistics}

Data throughout the text are expressed as mean \pm SD. Statistical analysis was performed using the Statistical Package for the Social Sciences (SPSS) version 19 software. Statistical comparisons among the experimental groups were done by analysis of variance (ANOVA) with post-hoc Scheffé's test. $p<0.05$ was considered significant.

\section{Results and Discussion}

Previously to the in vitro assays, a morphological, structural and physicalchemical characterization of the tooth samples was carried out. Fig. 2 shows the tooth bleaching effects on the morphology of human enamel and dentin. SEM micrographs show notable changes concerning the enamel morphology of the bleached-enamel compared with the unbleached sample. Whereas typical enamel structure prism is displayed in the untreated sample (Fig. 2A), after bleaching, this typical morphology was lost, appearing deep longitudinal cavities through the enamel structure (Fig. 2B). This is in agreement with the studies by Hanks et al. (33), showing that bleaching agents 
increased enamel porosity owing to matrix disruption, due to free radical oxidation of its structural components. Furthermore, direct ESEM evaluation of enamel-dentin and dentin zones evidenced morphological changes in the most superficial parts of the enamel without altering the dentin area after bleaching treatment (Fig.2C and D). Fig. 3 and Table 1 summarize the results derived from EDS and EPMA analyses before and after bleaching. The chemical characterization showed no significant variations in the composition in both enamel and dentin zones after bleaching treatment. These results are consistent with XRD analyses (data not shown), which do not support any structural and microstructural change of the apatite phase after this bleaching treatment (28). In fact, XRD studies showed diagrams corresponding to the apatite with profiles "more crystalline" for the enamel part than for dentin whose diagrams were wider and with less-defined peaks. No modifications in the intensity or the position of the peaks were observed after bleaching, indicating that the crystallinity of the apatite remains unaltered in both zones (enamel and dentin). These findings are in agreement with our previous studies, showing that neither the structural nor the chemical features of both enamel and dentin were altered after the same type of bleaching treatment as used here (28).

Table 1: Chemical composition as atomic percent of the different elements obtained by EPMA and EDS analysis.

\begin{tabular}{|c|l|l|l|l|l|l|}
\hline Area/Elements & Ca & P & Mg & Cl & F & Na \\
\hline \multicolumn{7}{|c|}{ EPMA* } \\
\hline Enamel $_{\text {Unbleached }}$ & $61.0 \pm 3.0$ & $35.7 \pm 2.7$ & $0.6 \pm 0.2$ & $1.25 \pm 0.7$ & $0.63 \pm 0.3$ & $0.82 \pm 0.8$ \\
\hline Enamel $_{\text {Bleached }}$ & $61.0 \pm 3.5$ & $35.0 \pm 2.6$ & $0.7 \pm 0.3$ & $1.14 \pm 0.8$ & $0.70 \pm 0.5$ & $1.40 \pm 0.7$ \\
\hline \multicolumn{7}{|c|}{ EDS } \\
\hline Enamel $_{\text {Unbleached }}$ & $60.4 \pm 2.3$ & $37.5 \pm 1.8$ & $0.5 \pm 0.2$ & $1.2 \pm 0.3$ & - & $1.0 \pm 0.5$ \\
\hline Enamel $_{\text {Bleached }}$ & $60.6 \pm 2.1$ & $36.8 \pm 1.1$ & $0.7 \pm 0.3$ & $1.3 \pm 0.3$ & - & $1.2 \pm 0.5$ \\
\hline Dentin $_{\text {Unbleached }}$ & $61.4 \pm 2.0$ & $35.9 \pm 2.0$ & $0.5 \pm 0.3$ & $1.3 \pm 0.7$ & - & $2.3 \pm 0.6$ \\
\hline Dentin $_{\text {Bleached }}$ & $62.5 \pm 2.0$ & $35.4 \pm 2.0$ & $0.8 \pm 0.5$ & $1.1 \pm 0.8$ & - & $2.2 \pm 0.6$ \\
\hline
\end{tabular}

* Note that this was conducted in the most external surface of the enamel. Only small traces of fluorine were observed in the outermost surface of the teeth.

Data are mean \pm SD of 15 determinations performed in different areas of five different tooth specimens. 
Fig. 4 shows the micrographs of the sessile water drops onto the surfaces of tooth before and after treatment. The initial contact angles, measured one second after water drop deposition, were $65^{\circ}$ and $40^{\circ}$ for unbleached and bleached tooth, demonstrating a slight increase of the wettability, which could be ascribed to the increase of porosity after bleaching.

In the present study, we found that the number of RAW-264.7 cells grown on bleached human dentin was higher than that on unbleached dentin. The presence of either osteostatin or FGF-2 showed a similar tendency to normalize these increased values (not shown). On the other hand, cells cultured on bleached dentin disks showed a moderate but significant decrease (about 30\%) in cell viability in comparison to unbleached controls (showing on average $80 \%$ viability). This action was mimicked by FGF-2 but prevented by osteostatin which similarly increased cell viability in both types of dentin studied (not shown). The bleaching pre-treatment failed to significantly affect the intracellular cell content of ROS at the end of the study. However, FGF-2 enhanced this content whereas osteostatin decreased ROS even in control cells grown on unbleached dentin (Fig.5A). Thus, it appears that ROS production is independent of bleaching, and osteostatin or FGF-2 in fact may have effects independent of bleaching on these cells. Secretion of IL-6 was dramatically decreased in these osteoclast-like cells maintained on bleaching pre-treated dentin, with or without addition of FGF-2 or osteostatin (Fig.5B). TNF $\alpha$ secretion by these cells was also decreased in this bleaching environment, but this was compensated for by osteostatin, which per se dramatically stimulated the secretion of this cytokine in cell cultures on unbleached dentin (Fig.5C).

The capacity of RAW-264.7 cells cultured in the experimental conditions described above to resorb both types of dentin studied was next examined by SEM. We found different patterns of pits produced by these cells on dentin depending on the different experimental settings. As shown in Fig.6, the resorption areas observed on 
bleaching-treated dentin had a larger diameter that on untreated control dentin. This

\section{Acknowledgements}

The authors deny any conflicts of interest. This study was supported by research grants from the Spanish Ministerio de Ciencia e Innovación (MAT2012-35556), Ministerio de Economía y Competitividad (MAT2013-43299-R), Instituto de Salud Carlos III (PIE13/00051) and Agening Network of Excellence (CSO2010-11384-E). The authors 
thank the technical support of the staff of the ICTS National Center for Electron Microscopy and CAI of Cytometry and Fluorescence Microscopy Center, UCM, Madrid. M.C. Matesanz and J. Linares are greatly indebted to MICINN and CIBER$\mathrm{BBN}$, respectively, for predoctoral fellowships.

\section{References}

1. GlimcherMJ.Role of collagen fibrils and collagen-phosphoprotein complexes in vitro and in vivo.Anat $\operatorname{Rec} 1989 ; 224: 139-53$.

2. Mann S. Molecular recognition in biomineralization. Nature 1988;332:119-24.

3. McKee MD, Addison WN, Kaartinen MT. Hierarchies of extracellular matrix and mineral organization in bone of the craniofacial complex and skeleton. Cells Tissues Organs 2005;181:76-188.

4. Vallet-Regí M, Arcos D. Biomimetic Nanoceramics in Clinical Use: From Materials to Applications. Cambridge, UK: RSC Pub; 2008.

5. Vallet-Regí M, González-Calbet JM. Calcium phosphates as substitution of bone tissues. Prog Solid State Chem2004;32:1-31.

6. Boskey AL. Assessment of bone mineral and matrix using backscatter electron imaging and FTIR imaging. Current Osteoporosis Reports 2006;4:71-5.

7. Cazalbou S, Combes C, Eichert D, Rey C. Adaptativephysico-chemistry of biorelated calcium phosphates. J Mater Chem 2004;14:2148-53.

8. Pasteris JD, Wopenka B, Valsami-Jone E. Bone and Tooth Mineralization: Why Apatite? Elements 2008;4:97-104.

9. Patel S, Kanagasingam S, Pitt FT. External cervical resorption: A review. J Endod 2009;35:616-25.

10. Zhou YZ, Cao Y, Liu W, Chu C-H, Li Q-L. Polydopamine-induced tooth remineralization. ACS Appl Mater Interfaces. 2012;4:6901-10.

11. Gold SI, Hasselgren G. Peripheral inflamatory root resorption: a review of the literature with case reports. J ClinPeriodontol. 1992;19:523-34.

12. Madison S, Walton R. Cervical root resorption following bleaching of endodontically treated teeth. J Endod 1990;16:570-4.

13. Toledano M, Yamauti M, Osorio E, Osorio R. Bleaching agents increase metalloproteinases mediated collagen degradation in dentin. $\mathbf{J}$ Endod 2011;37:1668-72. 
14. Eimar H, Siciliano R, Abdallah MN, Nader SA, Amin WM, Martínez PP, Celemin A, Cerruti M, Tamimi F. Hydrogen peroxide whitens teeth by oxidizing the organic structure. J Dent 2012; 40:25-33.

15. Camargo SEA, Valera MC, Camargo CHR, Mancini MNG, Menezes MM. Penetration of $38 \%$ hydrogen peroxide into the pulp chamber in bovine and human teeth submitted to office bleach technique. J Endod 2007;33:1074-1077.

16. Bonafé E, Bacovis CL, Iensen S, Loguercio AD, Reis A, Kossatz S. Tooth sensitivity and efficacy of in-office bleaching in restored teeth. J Dent 2013; 41:363-369.

17. Badran Z, Pilet P, Verron E, Bouler J-M, Weiss P, Grimandi G, Guicheux J, Soueidan A. Assay of in vitro osteoclast activity on dentine, and synthetic calcium phosphate bone substitutes. J Mater Sci: Mater Med 2012;23:797-803.

18. Li C-Y, Prochazka J, Goodwin AF, Klein OD. Fibroblast growth factor signaling in mammalian tooth development. Odontology 2014; 102:1-13.

19. Lozano D, Feito MJ, Portal-Núñez S, Lozano RM, Matesanz MC, Serrano MC, Vallet-Regí M, Portolés MT, Esbrit P. Osteostatin improve the osteogenic activity of fibroblast growth factor 2 inmobilized in Si-dopped hydroxyapatite in osteoblastic cells. ActaBiomater 2012; 8:2770-7.

20. Zuo J, Jiang J, Dolce C, Holliday LS. Effects of basic fibroblast growth factor on osteoclasts and osteoclast-like cells. Biochem Biophys Res Comm 2004; 318:162-7.

21. Lu X, Su N, Yang J, Huang W, Li C, Zhao L, He Q, Du X, Shen Y, Chen B, Chen L. Fibroblast growth factor receptor 1 regulates the differentiation and activation of osteoclasts through Erk1/2 pathway. BiochemBiophys Res Comm 2009; 390:494-9.

22. Toribio RE, Brown HA, Novince CM, Marlow B, Hernon K, Lanigan LG, Hildreth BE 3rd, Werbeck JL, Shu ST, Lorch G, Carlton M, Foley J, Boyaka P, McCauley LK, Rosol TJ. The midregion, nuclear localization sequence, and C terminus of PTHrP regulate skeletal development, hematopoiesis, and survival in mice. FASEB J 2010; 24:1947-57.

23. Cornish J, Callon KE, Lin C, Xiao C, Moseley JM, Reid IR. Stimulation of osteoblast proliferation by C-terminal fragments of parathyroid hormone-related protein. J Bone Miner Res 1999;14:915-22. 
24. Lozano D, Manzano M, Doadrio JC, Salinas AJ, Vallet-Regí M, GómezBarrena E, Esbrit P. Osteostatin-loaded bioceramics stimulate osteoblastic growth and differentiation. Acta Biomater 2010; 6:797-803.

25. Fenton AJ, Kemp BE, Kent GN, Moseley JM, Zheng MH, Rowe DJ, Britto JM, Martin TJ, Nicholson GC. A carboxyl-terminal peptide from the parathyroid hormone-related protein inhibits bone resorption by osteoclasts. Endocrinology 1991;129:1762-68.

26. Cornish J, Callon KE, Nicholson GC, Reid IR. Parathyroid hormone-related protein-(107-139) inhibits bone resorption in vivo. Endocrinology 1997;38: 1299-304.

27. Kaji H, Sugimoto T, Kanatani M, Fukase M, Chihara K. Carboxyl-terminal peptides from parathyroid hormone-related protein stimulate osteoclast-like cell formation. Endocrinology 1995; 136:842-8.

28. Izquierdo-Barba I, Torres-Rodríguez C, Matesanz E, Vallet-Regí M. New approach to determine the morphological and structural changes in the enamel as consequence of dental bleaching. Materials Letters, 2015;14:302-306.

29. Bracco G, Holst B. Surface Science Techniques, Springer Series in Surface Sciences 51, Editorial Springer-Verlag Berlin Heidelberg 2013. DOI: 10.1007/978-3-642-34243-1_1.

30. Hotokezaka H, Sakai E, Kanaoka K, Saito K, Matsuo K, Kitaura H, Yoshida N, Nakayama K. U0126 and PD98059, specific inhibitors of MEK, accelerate differentiation of RAW264.7 cells into osteoclast-like cells. J BiolChem 2002; 277:47366-72.

31. Matesanz MC, Linares J, Lilue I, Sánchez-Salcedo S, Feito MJ, Arcos D, Vallet-Regí M, Portolés MT. Nanocrystalline silicon substituted hydroxyapatite effects on osteoclast differentiation and resorptive activity. J Mater Chem B 2014; 2:2910-19.

32. Feito MJ, Lozano RM, Alcaide M, Ramírez-Santillán C, Arcos D, Vallet-Regí M, PortolésMT.Immobilization and bioactivity evaluation of FGF-1 and FGF-2 on powdered silicon-doped hydroxyapatite and their scaffolds for bone tissue engineering. J Mater Sci Mater Med 2011; 22:405-16.

33. Hanks CT, Fat JC, Wataha JC, Corcoran JF. Cytotoxicity and dentin permeability of carbamide peroxide and hydrogen-peroxide vital bleaching materials, in vitro. J Dent Res 1993;72:931-8. 
34. Kitaura H, Nagata N, Fujimura Y, Hotokezaka H, Tatamiya M, Nakao N, Yoshida N, Nakayama K. Interleukin-4 directly inhibits tumor necrosis factor$\alpha$-mediated osteoclast formation in mouse bone marrow macrophages. Immunol. Lett. 2003;88:193-9. 


\section{Figure captions}

Fig. 1. Biological apatites are components of both bone and tooth enamel. (Left) A representative long bone (femur; whole tissue), an XRD diagram and scanning electron micrograph of the trabecular bone area are shown. (Right) This shows a cross section of human molar structure (whole tissue), an XRD diagram corresponding to enamel showing higher crystallinity of apatite phase than in bone, and scanning electron micrograph showing the typical enamel structure prisms (8).

Fig. 2. Representative ESEM micrographs of corresponding to tooth enamel and dentin zones before and after bleaching treatment, respectively.

Fig. 3. EDS analysis corresponding to both enamel and dentin areas before and after tooth bleaching. The different locations analyzed are depicted as pink points in the corresponding SEM micrographs.

Fig. 4. Evaluation of surface wettability. Representative micrographs of a water drop onto either an unbleached tooth (left) or a bleached tooth (right) are shown.

Fig. 5. Effects of osteostatinand FGF-2 onintracellular reactive oxygen (ROS) content (A) and IL-6 (B) and TNF $\alpha$ secretion (C), in osteoclast-like cells cultured on bleached dentin (B) or unbleached dentin (UB). Controlswithoutosteostatinor FGF-2 werecarriedout in parallel. Data are expressed as means \pm SD. All the experiments were performed twice and carried out in triplicate. Statistical significance: $* p<0.05$, $* * \mathrm{p}<0.01, * * * \mathrm{p}<0.005$ (compared to control without osteostatin or FGF) and $\# \mathrm{p}<0.05$, $\# \# \mathrm{p}<0.01, \# \# \mathrm{p}<0.005$ (compared to unbleached dentin, UB).

Fig. 6. Representative SEM images of unbleached (UB) or bleached (B) dentin surfaces after culture of RAW-264.7 cells in osteoclast differentiation medium in the absence or presence of either osteostatin or FGF-2. Representative diameters of resorption lacunae are shown in each case. 


\section{Figures}

Fig. 1:
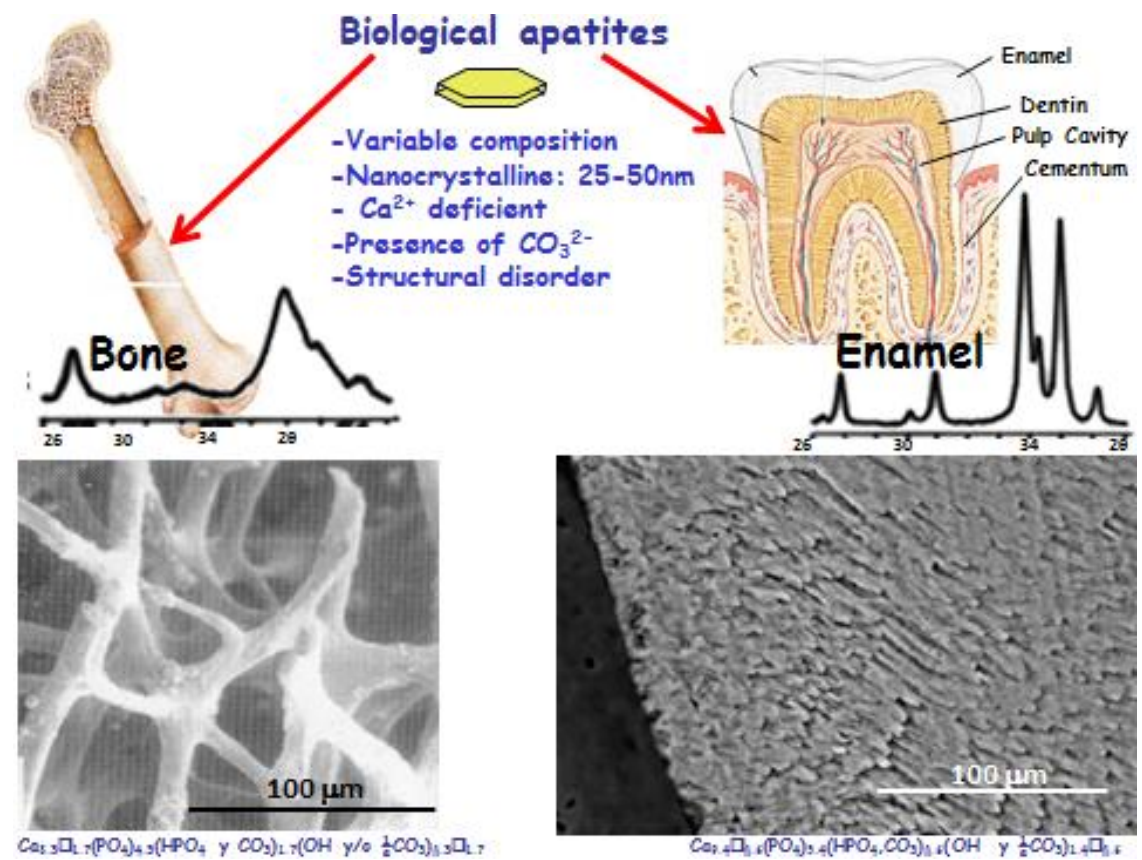

Fig. 2:

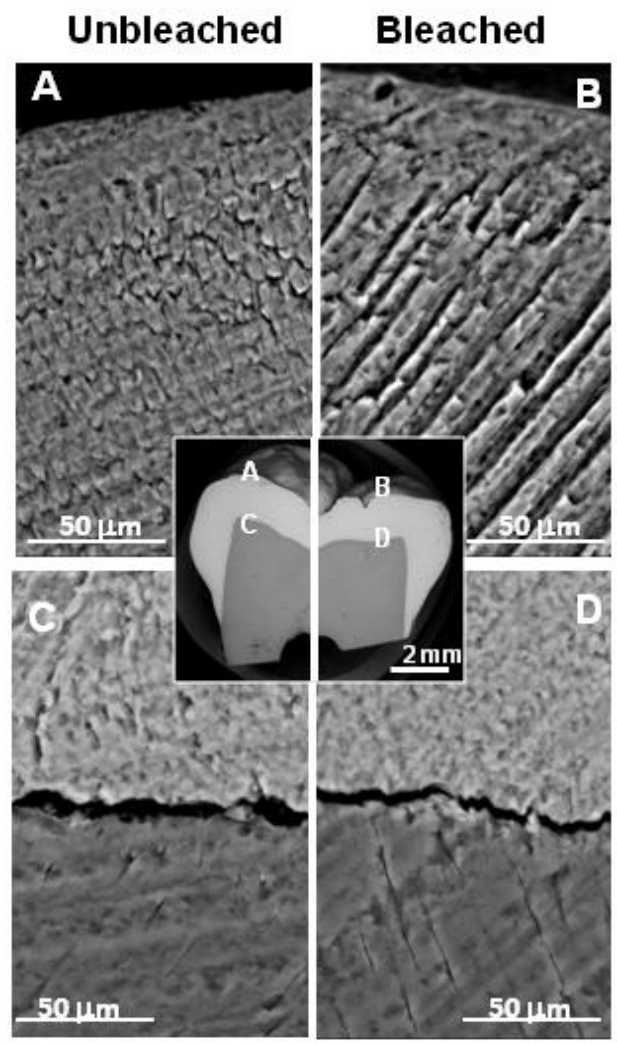


Fig. 3:

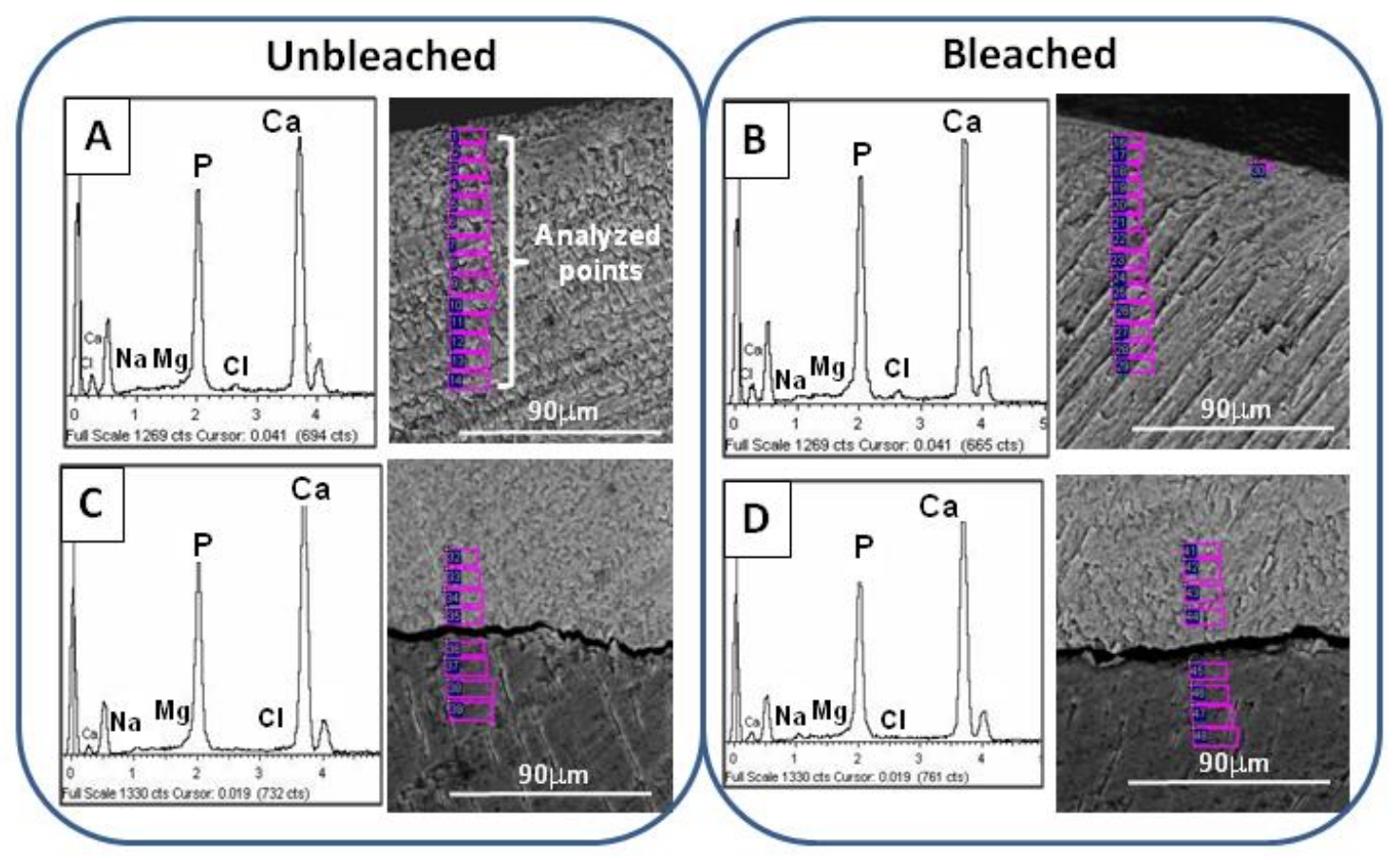

Fig. 4:
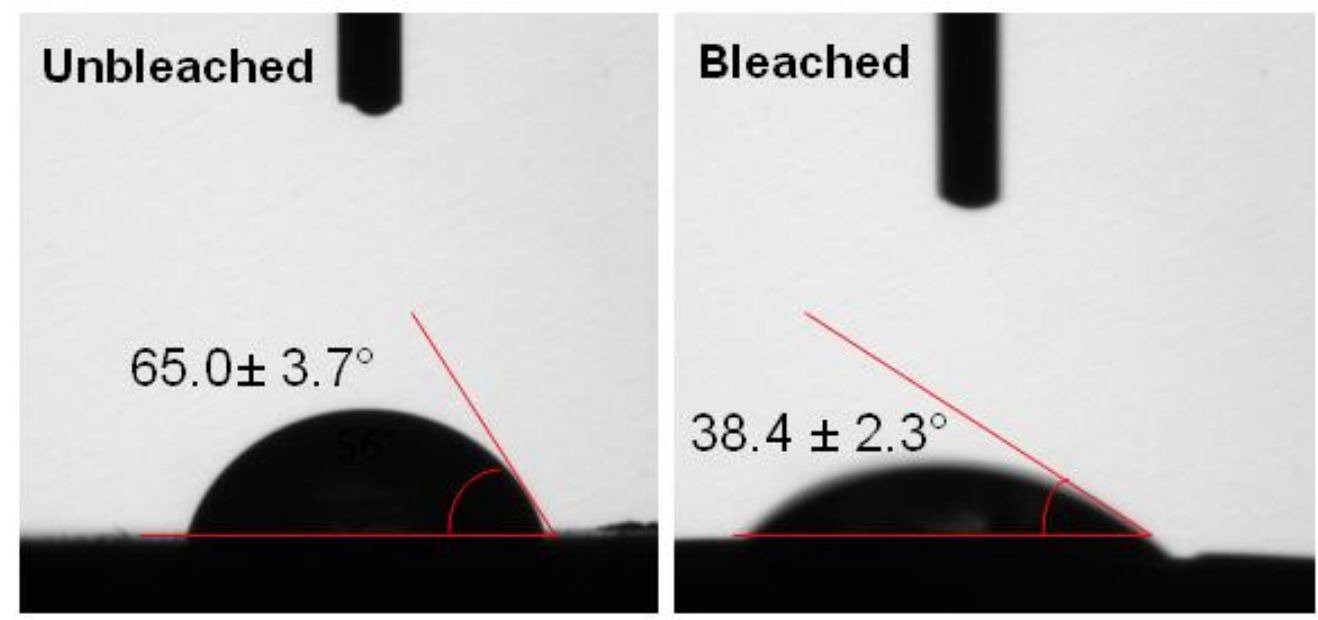
Fig. 5:
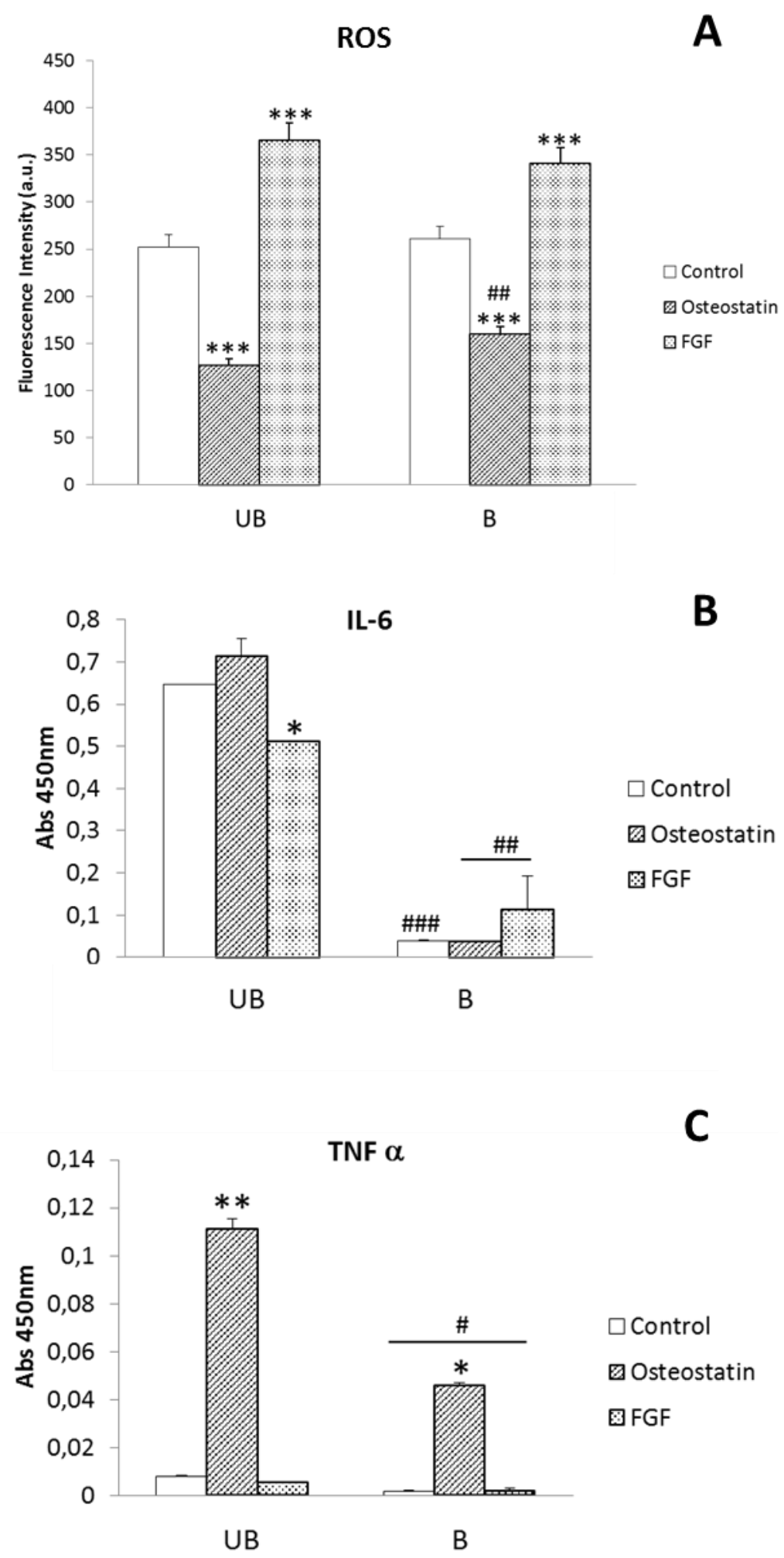
Fig. 6:

1
2
3
3
4
5
6
7
7
8
9
10
11
12
13
14
15
16
17
17
18
19
29
21
21
22
23
24
25
26
27
27
28
29
39
39
31
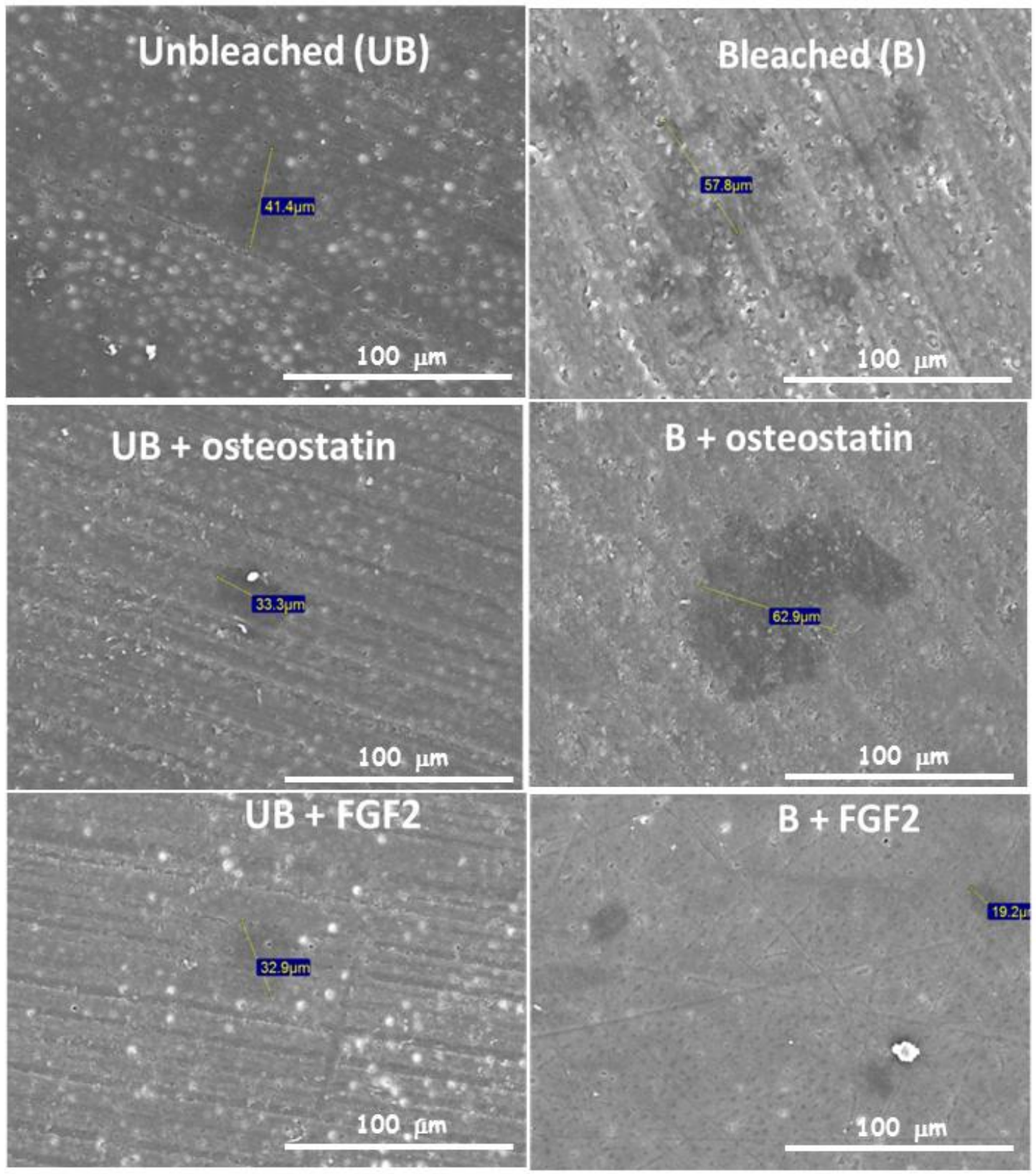

45

48

49

50

51

54

55

56

60 